\title{
ATTACHMENT THEORY WITHIN CLINICAL SUPERVISION: APPLICATION OF THE CONCEPTUAL TO THE EMPIRICAL
}

Elizabeth R. Wrape, M.S.

Dissertation Prepared for the Degree of

DOCTOR OF PHILOSOPHY

UNIVERSITY OF NORTH TEXAS

August 2015

\author{
APPROVED: \\ Jennifer L. Callahan, Major Professor \\ Randall J. Cox, Committee Member \\ Edward Watkins, Committee Member \\ Vicki Campbell, Chair of the Department of \\ Psychology \\ Costas Tsatsoulis, Interim Dean of the \\ Toulouse Graduate School
}


Wrape, Elizabeth R. Attachment theory within clinical supervision: Application of the conceptual to the empirical. Doctor of Philosophy (Clinical Psychology), August 2015, 69 pp., 7 tables, references, 99 titles.

Attachment theory has established itself as applicable to many types of relationships, encompassing caregiver-child, romantic, interpersonal, and psychotherapeutic interactions. This project sought to investigate the application of attachment theory to clinical supervision. Using suggestions put forth in previous work by Watkins and Riggs, this study examined the dyadic interactions inherent in both supervision and attachment. Using the working alliance as determination of the quality of supervision, attachment styles, leader-follower attachment, and attachment-based expectations were explored as predictors for supervisor-trainee dyad outcome in a training clinic for doctoral psychology students. The study design is longitudinal and prospective. Findings indicate the necessity of measurement of supervisory-specific attachment rather than general attachment, the stability of working alliance over time, and the large contribution of the leader-member attachment framework to the understanding of supervisory attachment. Implications include the importance of maintaining hierarchical, evaluative boundaries within supervisory relationship, consistent with a leader-follower dynamic. 
Copyright 2015

by

Elizabeth R. Wrape 


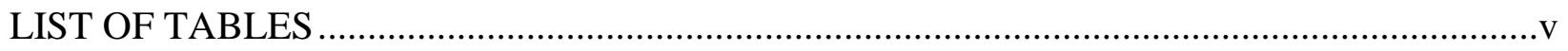

\section{Chapters}

I. REVIEW OF LITERATURE

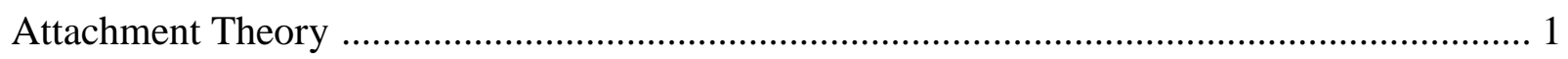

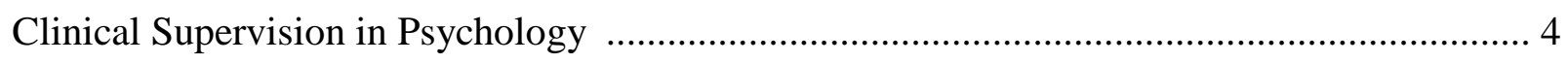

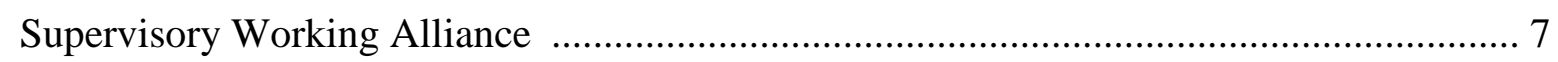

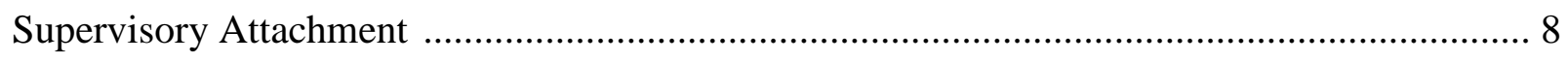

Trainee Attachment ............................................................................................

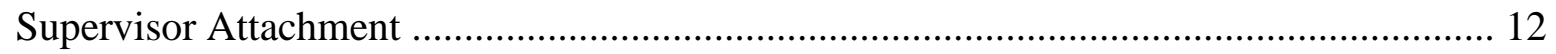

Supervisory Attachment in Dyadic Interactions .......................................................15

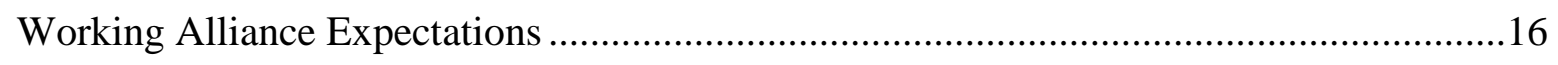

Measurement of Supervisory Attachment ...................................................................17

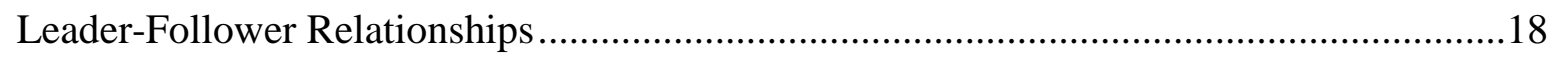

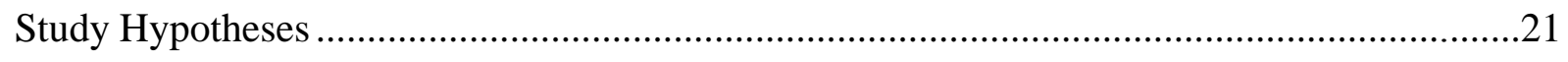

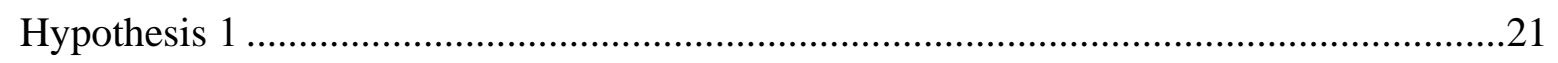

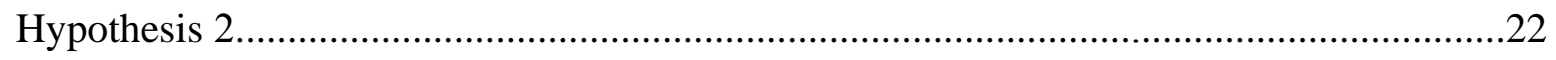

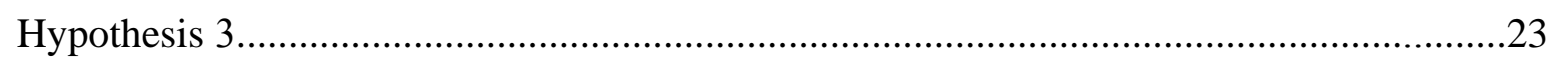

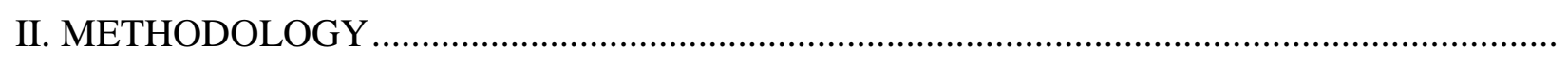

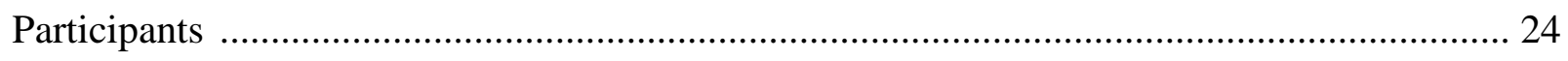

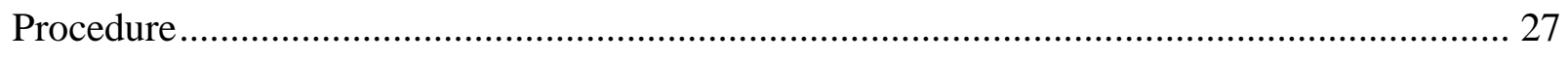

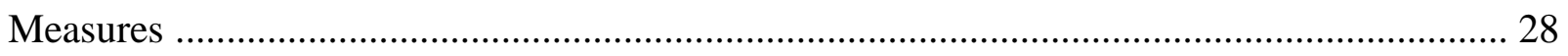


Leader-Member Exchange (LMX) ................................................................................ 29

The Relationship Questionnaire (RQ) ………………….............................................. 29

The Relationship Structures Questionnaire (ECR-RS) ……………………………………..... 30

Working Alliance Inventory- Short Version (WAI-SV) ........................................................ 31

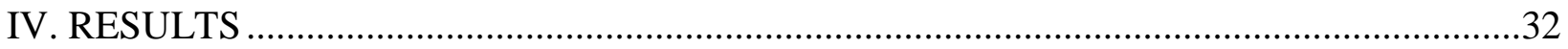

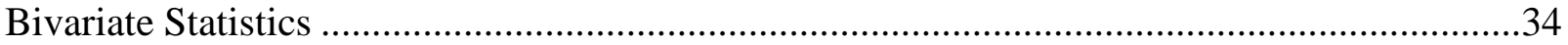

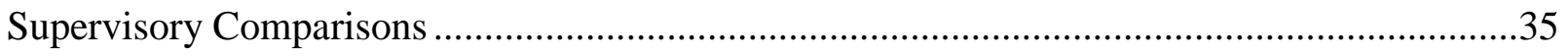

Trainee Attachment Style .......................................................................................................36

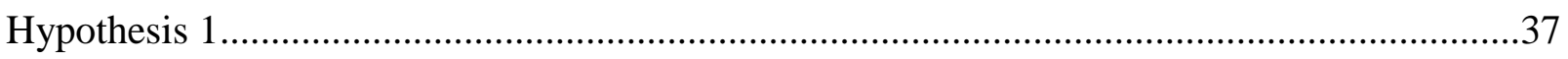

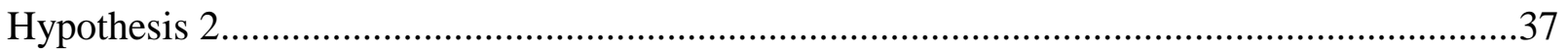

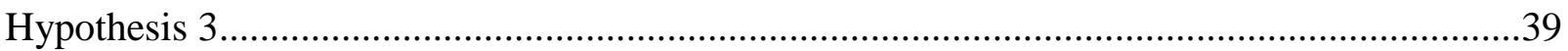

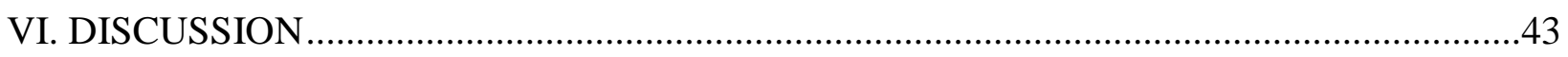

General vs. Supervision-Specific Attachment .............................................................................43

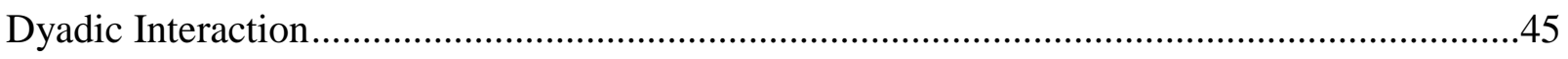

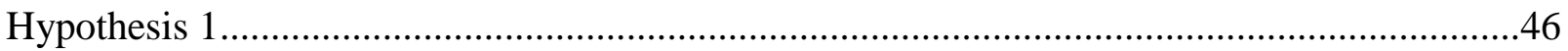

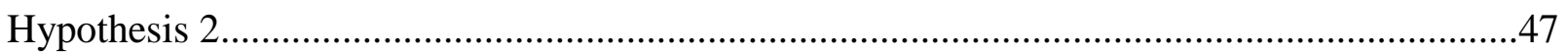

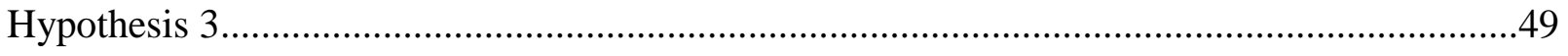

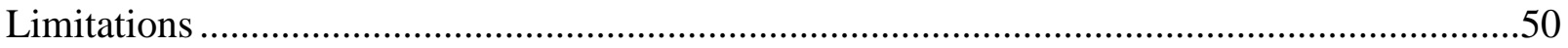

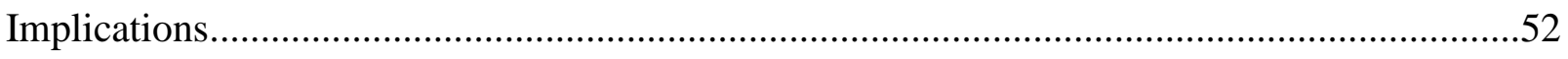

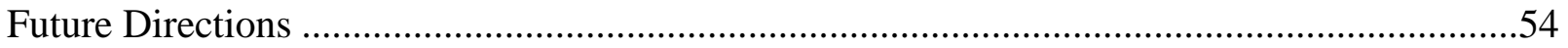

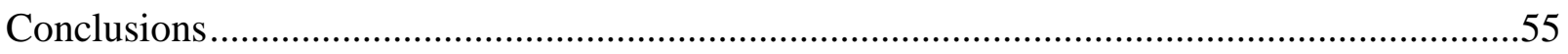

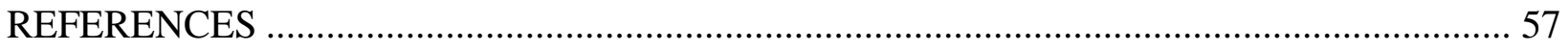




\section{LIST OF TABLES}

Page

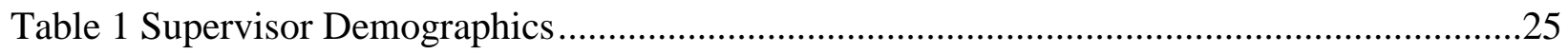

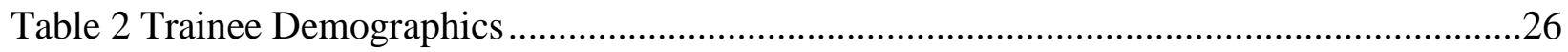

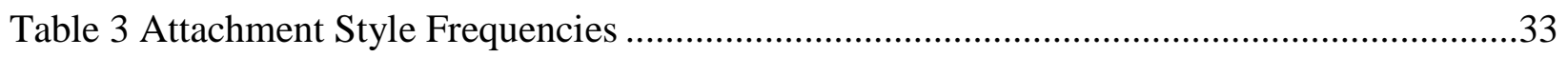

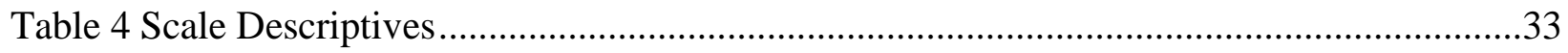

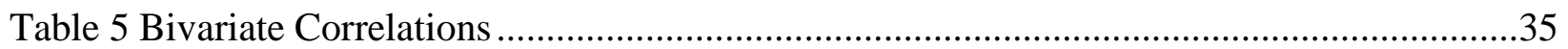

Table 6 Hierarchical Regression Analysis Predicting Time Two WAI-SVEE Scores from

Attachment and Leader-Member Exchange Interaction .....................................................40

Table 7 Hierarchical Regression Analysis Predicting Time Two WAI-SVEE Scores from

Attachment, Trainee Leader-Member Exchange, and Leader-Member Exchange Interaction .....41 


\section{CHAPTER I}

\section{REVIEW OF THE LITERATURE}

While the importance of supervision in the formation of future psychologists cannot be overstated, it is heretofore an understudied component of clinical training. Alternatively, the theory of attachment is pervasive in its application to numerous relationship dynamics including mother-child, peer, and romantic relationships (Connors, 2011; Fraley \& Shaver, 2000; Mikulincer, Florian, Cowan, \& Cowan, 2002; Mikulincer \& Shaver, 2007a). Limited research has occurred in the intersection of attachment and supervision, and there are still many avenues to explore. This project sought to apply the theory of attachment to supervision, building upon previous research in both areas separately and together, and further explicating the applicability of attachment dynamics in the supervision relationship.

\section{Attachment Theory}

At its inception, attachment theory was developed to explain infant-caregiver interactions (Bowlby, 1979/1988). Put into empirical practice through the Strange Situation experiment, attachment theory conceptualized infant behavior through a dyadic model, parsing out "styles" based on patterns between an infant and caretaker (Ainsworth, Blehar, Waters, \& Wall, 1978). Through more research, these styles were hypothesized to generalize beyond infancy into adult relationships (Cassidy \& Shaver, 2008; Feeney, 1999; Hazan \& Shaver, 1987; Rubenstein \& Shaver, 1982). While strict carryover of infant styles to adult relationships has not been fully supported for each individual, research has demonstrated that attachment pattern in infancy does affect behavior and general attachment style in adulthood (Ainsworth, 1989; Rubenstein \& Shaver, 1982). Review of empirical findings regarding attachment in infancy and adulthood is 
far beyond the scope of this project (for reviews see Cassidy \& Shaver, 2008; Fraley \& Shaver, 2000; Mikulincer \& Shaver, 2007a; Rholes \& Simpson, 2004); however, there is great commonality in the foundation of the literature, allowing for an overview of the theory without comprehensive cataloging of each study.

A common thread within models of attachment is the concept of the internal working model (IWM). More specifically, an internal working model is how an infant internalizes the outside world and generalizes that view towards self and others (Bowlby, 1977). This results in expectations and beliefs about and of significant others. For instance, an infant with a caretaker that inconsistently responds may then view future others as inconsistent, creating a pattern of behavior in reaction to that expectation. Research has shown that this view is subject to alteration given environmental circumstances (referred to as lawful discontinuity, e.g. therapy, death), but can be long lasting (Bowlby, 1973; Harris, 2004). With this mechanism in common, what follows is a brief description of the different models of attachment (and corresponding styles) in adult relationships in order to better contextualize the current project.

An attachment style is a pattern of behavior created through a person's IWM and previous experiences (Bowlby, 1977). Ainsworth and colleagues (1978) identified infant attachment styles in observation studies of infants and their caretakers. Infants were categorized into four styles: secure, ambivalent, avoidant, and disorganized. Similar in nature but renamed are adult attachment styles, which include secure, preoccupied, dismissing, and unresolved/fearful (Bartholomew \& Horowitz, 1991; Main, Kaplan, \& Cassidy, 1985). This model utilizes a two by two structure, with positive/negative views of self/other classifying a person in one category (Bartholomew \& Horowitz, 1991). Other studies have used continuous measurement of attachment avoidance and anxiety to place a person on a circumplex (e.g. high 
anxiety and avoidance is fearful; low anxiety and high avoidance, dismissing) (Brennan, Clark, \& Shaver, 1998; Fraley, Heffernan, Vicary, \& Brumbaugh, 2011; Mikulincer \& Shaver, 2007b). Though models and method of assessment differ, findings are similar in that adult attachment has been upheld as a major contributor in dyadic interactions.

For the purposes of the current study, the Bartholomew and Horowitz (1991) model of general adult attachment and the circumplex model of anxiety and avoidance for relationshipspecific attachment was used. In previous research these models have proved useful in conceptualizing a person’s approach to adult relationships including romantic (Ainsworth, 1989; Fraley \& Shaver, 2000), peer (Ainsworth, 1989), psychotherapeutic (Daniel, 2006), and supervisory (Pistole \& Watkins, 1995). Secure people differ from the insecure (subsuming preoccupied, dismissive, and fearful) in that their IWMs are positive for both self and other. Preoccupied attachment styles have a positive view of others and negative self-model, dismissing styles have a positive self-view and negative view of others, and fearful styles view both themselves and those around them negatively. Secure attachment results in less pathological attachment behaviors, such as those associated with insecure styles, including excessive demands (preoccupied) or withdrawal (dismissing and fearful). While the type of relationship itself will dictate the appropriateness and the context that these behaviors take place, there is consistency in the presence of these types of behaviors in their corresponding styles.

It should be noted, however, that one person does not determine the quality of the relationship based on his or her attachment style. Rather, there are more complicated dyadic patterns that emerge when considering interactions. Similar to systems and gestalt theories, the whole is greater than the sum of its parts (Mikulincer et al., 2002). The attachment style of one member of the dyad can either buffer or exacerbate the other member's behaviors; therefore, it is 
illuminating to examine outcomes in relation to the interaction of styles (Mikulincer et al., 2002). Research of this nature is difficult to accomplish, and in many cases has been skipped in favor of examining one member's style and the perceived style of the relationship partner (Fraley \& Shaver, 2000). This project attempted to weather this difficulty in order to capture more fully the intricacies involved in one specific type of adult relationship: clinical supervision.

\section{Clinical Supervision in Psychology}

Especially in the training of graduate students and early career psychologists, supervision is an invaluable resource. Bernard and Goodyear (2009) define supervision as the following: Supervision is an intervention provided by a more senior member of a profession to a more junior member or members of that same profession. The relationship is evaluative and hierarchical, extends over time, and has the simultaneous purposes of enhancing the professional services offered to the clients that she, or he, or they see, and serving as a gate-keeper for those who are to enter the particular profession. (p. 7)

Supervisors are responsible for many components of this unique relationship, as they are tasked with providing guidance and a safe environment for anxiety and confusion normative to the training of psychotherapists (Thomas, 2010). Additionally, Borders (1993) stated that effective supervisors see themselves as educators and trainees as learners, creating appropriate learning environments. Supervision is an integration of the roles of counselor, teacher, and consultation, and is used to cultivate development of skill sets and interpersonal strengths in trainees (Bernard \& Goodyear, 2009; Thomas, 2010).

There are numerous models describing the process and enactment of supervision (for reviews see Bernard \& Goodyear, 2009; Hess, 2008; Watkins, 1997). While the emphasis on 
interpersonal and relational components varies between models, no conceptualization of supervision exists devoid of the relationship. To illustrate this point, Watkins (2011) discussed three components of a supervision relationship including supervisory alliance, transferencecountertransference, and the real relationship (working alliance is covered in a subsequent section in this introduction). The real relationship was identified as personal interactions, feelings, thoughts, and behaviors that exist between the supervisor and trainee; any genuine care and appropriate feelings that do not exist within the supervisory working alliance are characterized as real relationship. This point indicates that there is a strong human component to supervision and that research on this subject is essential to understanding the mechanisms behind this supervision process.

As with all human interaction, there are two-way factors to consider. The idea of transference-countertransference represents this factor in the supervisory alliance. Transference relates to thoughts, feelings, and behaviors a trainee enact on their supervisor, usually relating to personal history or characteristics (Schamess, 2006). Ladany, Constantine, Miller, \& Erickson (2000) define supervisory countertransference is composed of supervisor feelings, thoughts, or behaviors that could be exaggerated or distorted reactions to interpersonal or personal issues. Bernard (2005) discusses the need to address these supervisor-trainee factors in a more balanced manner, rather than viewing only the trainee characteristics as (usually negatively) impactful. Whether or not one is using this interactional framework, negative supervisory relationships are associated with worse outcomes for the trainee. According to Ramos-Sanchez and colleagues (2002), 21.4\% of psychology students and interns have had negative experiences in supervision. In another study, 59\% of trainees reported that they had received inadequate supervision either in their current or former relationships; 27\% reported that previous supervisors had been harmful 
(Ellis, 2001). Only in acknowledging the problem of inadequate or poor supervision can we begin to examine it. Hess and Hess (2008) list effective strategies for both supervisors and trainees, stressing the dual responsibility of forming a positive supervisory working alliance. Many poor supervision relationships may have resulted from supervisor interpersonal process issues. These includes harsh and frequent criticism, unwillingness to meet the trainee's training needs, or distorted or unrealistic supervisor view of the trainee (Ladany et al. 1999; O’Connor, 2001; Ramos-Sanchez et al., 2002). While it is often the trainee's interpersonal or working style that enact a supervisor's countertransferential reactions, these responses can often stem from unresolved historical difficulties with the supervisor themselves (Ladany, Constantine, Miller, Erickson, \& Muse-Burke, 2000). Some supervisors, sometimes just from inexperience, have difficulty navigating the intense emotions of their trainee as they learn psychotherapy and interact with clients (Ellis, 2001).

Alternatively, a supervisor who can effectively manage trainee anxiety is beneficial to the relationship (Weatherford, O’Shaughnessy, Mori, \& Kaduvettoor, 2008). Trainees may need different environments depending on development; reducing role ambiguity is helpful in this regard (Goodyear \& Bernard, 2009; Hess, 2008; Olk \& Friedlander, 1992; Weatherford et al., 2008). Supervisors that have the ability to maintain the frame of the hierarchical relationship, evaluate appropriately, cultivate disclosure, and address trainee anxiety are more likely to nurture positive relationships (Bernard \& Goodyear, 2009; Weatherford et al., 2008). Good supervision can result in a trainee's internalization of the supervisor, preparing the clinician to become autonomous and self-supervising (Bernard \& Goodyear, 2009). Prior to explicating the model of supervision used in this project, further information about the supervisory working alliance is essential, as it is a primary mechanism in understanding supervisory interaction. 
Supervisory Working Alliance

Bordin (1983) extended the working alliance of psychotherapy to supervision. In psychotherapy, he hypothesized the three legs of the working alliance: task, bond, and goals. For supervision, he expanded to eight goals of supervisory working alliance including specific skill mastery, greater understanding of clients, process, concepts and theory, increased self-awareness, removal of personal and intellectual impediments to learning, research-related stimulation, and maintenance of client service. He posited that these goals are accomplished through the agreement, tasks, and bonds within a supervision relationship as well as a supervision contract.

Strong supervisory working alliance has been associated with more positive supervision process and outcome, buffering against irreparable ruptures, reducing role ambiguity and conflict, lower levels of stress in trainees, and a greater sense of control for trainees (Gnilka, Chang, \& Dew, 2011; Ladany, 2000; Ladany \& Friedlander, 1995; Thomas, 2010). Weaker supervisory alliance is correlated with lower level of trainee development (Ramos-Sanchez et al., 2002) and greater role ambiguity (Weatherford et al., 2008). While conflicts during supervision naturally occur, working alliance can be strengthened following a rupture if handled correctly (Ladany et al., 2000; Nelson, Barnes, Evans, \& Triggiano, 2008).

There are other factors that affect working alliance. Gunn and Pistole (2012) described the supervisory working alliance in a model integrating attachment. Trainee and supervisor selfviews, captured well in attachment constructs, are associated with the quality of the working relationship (Fitch, Pistole, \& Gun, 2010). For instance, trainees with positive self-views (secure and dismissing styles of attachment) rated working alliance with their supervisors higher than those with negative self-views (anxious and fearful). Further discussion of this topic will take place following an introduction to the attachment in supervision literature. 


\section{Supervisory Attachment}

The examination of attachment theory in the context of supervision is unique to many supervision models due to its consideration of individual characteristics of supervisors and trainees (White \& Queener, 2003). Relational in nature, Bowlby’s initial psychoanalytic framework has grown into a transtheoretical examination of relationships in supervision (Pistole \& Watkins, 1995; Watkins \& Riggs, 2012). Attachment patterns in supervision have begun to be examined in the last twenty years. To date, approximately 10 empirical studies have examined the supervision/attachment framework. Many of these studies have been conducted with social work/field work supervision; fewer have been applied to clinical supervision. Theoretically, however, there have been many more papers written about this topic, often utilizing case examples as illustrations. Hill (1992), Pistole and Watkins (1995), and Watkins (1995) were the first to consider attachment within the context of supervision. Hill connected the relational process of supervision to attachment all within the context of marital and family psychotherapy. While his discussion of attachment in supervision was brief, he highlighted the importance of these constructs for client outcomes, as many supervisory attachment issues may arise in the therapeutic relationship.

Subsequently, Pistole and Watkins give greater detail in their presentation of attachment theory’s relevance in supervision. Both describe the maladaptive behaviors that insecurely attached trainees may utilize in a supervisory relationship including compulsive self-reliance, anxious attachment, and compulsive care-giving. It was argued that these behaviors could not only negatively impact the relationship between the supervisor and the student, but the parallel process of clinician and client (Bennett, 2008b, Pistole, 2008; Pistole \& Watkins, 1995; Watkins, 
1995). Thereby, it is arguably crucial that examination of this framework continues, with emphasis on empirical evidence, in an effort to maximize client and training outcomes.

Most of the empirical literature has focused on attachment behaviors in trainees;

however, there has been limited exploration as to the role supervisors play as well. Theoretically, a positive supervisory relationship provides two components of a caregiving bond: a safe haven and a secure base. A safe haven refers to supervisory interventions such as reassurance and comfort, while a secure base can include supervisor actions such as guidance in problem solving and decision-making (Bennett \& Saks, 2006; Fitch \& Pistole, 2010; Pistole, 2008; Pistole \& Watkins, 1995). More discussion of these constructs will take place with regard to supervisor role in attachment.

More generally, however, implementation of these types of behaviors can be effective in creation of a positive supervisory relationship. For instance, Neswald-McCalip (2001) hypothesized that a supervisor that provides a secure base in supervision may assist in shifting a trainee’s IWM to a more secure view. Additionally, some see attachment as helpful in addressing ruptures in the supervision relationship (Ramos-Sanchez et al., 2002). What follows is a more detailed exposition of the individual roles of the supervisor and trainee. The trainee role will be discussed first, followed by supervisor, concluding with other relevant topics in the consideration of attachment theory in supervisory relationships.

\section{Trainee Attachment}

Trainee attachment styles manifest in various ways in supervision. Secure trainees are more likely to utilize the supervision relationship as a secure base, or a place to begin exploration of clinical work (Bennett, \& Deal, 2009; Fitch, Pistole, \& Gun, 2010; Neswald-McCalip, 2001; 
Pistole \& Watkins, 1995). Additionally, a secure IWM perceives help as accessible if needed. For a trainee, this may manifest as security in the knowledge that a supervisor is available in crisis and that rejection will not occur if questions arise. In addition to the positive model of their supervisor and others, these trainees view themselves in a positive manner. This can facilitate disclosure, rapport with supervisor, perceptions of supervisor support, and an overall picture of a positive supervision experience (Bennett \& Saks, 2006; Gunn \& Pistole, 2012; Riggs \& Bretz, 2006). It is important to note that when faced with certain situations, such as client crises or novel experiences, secure trainees will still exhibit anxiety. However, it is the trainee's response to that anxiety that determines his or her supervisory attachment (Pistole, 2008).

Alternatively, insecure trainees report either significantly more (anxious attachment) or significantly less emotional (avoidant attachment) reactivity in supervision than secure trainees (Pistole, 2008). Supervisors may be viewed as unavailable or inconsistent, and repeated reassurance may be needed for trainees to function. In addition, insecure attachment can also have an impact on trainee internalizations of supervisor feedback and self-perception of his or her abilities. An avoidant trainee may deny his or her needs, feel discomfort with closeness or disclosure, and reject the suggestions of others, whereas an anxiously attached student may appear dependent and self-doubting about his or her capabilities (Pistole \& Watkins, 1995).

In one study, anxious trainees rated themselves as lower in self-awareness and motivation and more dependent on their supervisor overall (Deal, Bennett, Mohr, \& Hwang, 2011). In opposition to avoidant trainees, however, the anxious students perceived improvement in those areas more quickly over the course of their training. This progress could be explained with the theory that anxiously attached students are more likely to seek help, even if it appears more needy and self-effacing (Neswald-McCalip, 2001). In addition, compulsive self-reliance has 
been directly associated with poor supervisory working alliance, though at first the level of trainee independence may be impressive to the supervisor (Dickson, Moberly, Marshall, \& Reilly, 2011; Riggs \& Bretz, 2006).

Insecure attachment in trainees deserves further parsing into preoccupied, dismissing, and fearful attachments. However, many theoretical and empirical studies did not use the Bartholomew and Horowitz (1991) model, and thus the findings are more general to anxious or avoidant styles. There are a few studies that examined all three adult insecure styles, however. For instance, a dismissing trainee (positive view of self, negative of others) is more likely to be compulsively self-reliant, neglecting to receive or integrate feedback and therefore may inhibit growth in his or her skill set (Riggs \& Bretz, 2006, Watkins, 1995). Alternatively, a preoccupied style (negative view of self, positive view of others) is fixated on others' perceptions, and thereby this trainee be uncomfortable with the feedback process and seek constant reassurance of his or her worthiness (Renfro-Michel \& Sheperis, 2009). Finally, a fearful style mixes desire for intimacy with distance, seeking feedback but afraid of receiving it (Pistole \& Watkins, 1995). An unpublished dissertation from 2003 cited by several studies (Bennett, 2008b; Deal et al., 2011; Bennett, Mohr, Deal, \& Hwang, 2011; Renfro-Michel \& Sheperis, 2009) found a negative association between fearful trainees, overall professional development, and investment in counseling and supervision.

Trainee attachment appears to affect ratings of supervisory working alliance, as well. In a study of attachment, working alliance, and trainee training level, Renfro-Michel \& Sheperis (2009) found that styles with positive views of self (secure and dismissing) rated working alliance with their supervisors higher than those with negative views of self. Trainee rated working alliance styles from highest to lowest according to mean were secure, dismissing, 
fearful, and preoccupied. In that same study, the authors concluded that level of trainee training (pre-practicum, practicum, or internship) did not affect attachment orientation or working alliance scores. Results from White and Queener (2003) supported the lack of association between experience level and working alliance.

The previous finding is not consistent throughout the literature, however. Bennett and Deal (2009) suggest that there is a strong association between attachment and the level of student development. Attachment style and developmental level can interact; certain stages of development are more likely to activate attachment behaviors. For instance, early training is a common time for uncertainty and proximity-seeking behaviors to occur, but termination of training can elicit similar feelings, as well (Bennett et al., 2013; Riggs \& Bretz, 2006). Marmarosh and colleagues (2013) found that fearful attachment (high anxiety and high avoidance) to supervisors and avoidant general attachment predicted lower self-rated counseling self-efficacy. Further supporting these assertions, Foster, Licthenberg, and Peyton (2007) demonstrated an empirical association between trainee attachment style and self-rated development. It should be noted that this connection was non-significant when observer reports of student development were used. Therefore, it is logical to assume that attachment styles strongly influence the way students view themselves professionally even if the reality may be somewhat different.

Supervisor Attachment

Less research has been attempted with regard to supervisor attachment style. Some writings conceptualize the supervisor role as indicative of a caregiver role (complementary; Bennett \& Deal, 2009, Fitch, Pistole, \& Gun, 2010; Neswald-McCalip, 2001; Pistole, 2008). 
Other research uses general attachment style as a predictor of working alliance in supervision (reciprocal). One common thread, however, is that the supervisor's response to the trainee's attachment cues is highly impactful for the alliance. Attachment cues may take the form of excessive anxiety, anger, proximity seeking, skill regression, or halted learning (Pistole, 2008). Thereby, it is the supervisor's responsibility to recognize and respond to these behaviors (Neswald-McCalip, 2001; Pistole, 2008; Riggs \& Bretz, 2006). This responsibility is with the caveat put forth by Watkins (1995) that supervision and psychotherapy are distinct. More specifically, supervisors should not make concessions for insecure styles, but rather guide and encourage (Goodyear \& Bernard, 2009; Hess, 2008; Thomas, 2010). Whether the supervisor response to trainee attachment cues is better explained a reciprocal or complementary relationship is unknown, but some authors argue that a combination of both characterizes the supervisory relationship (Bennett \& Deal, 2009; Neswald-McCalip, 2001; Watkins \& Riggs, 2012).

Fitch, Pistole, and Gunn (2010) proposed the attachment-caregiving model of supervision (ACMS), arguing that bond and relationship are essential components of student skill building. In addition, the model emphasizes that supervisor sensitivity, flexibility, and responsiveness (together forming the "safe haven”) determines the outcome after a trainee’s attachment system is activated (e.g. after an especially difficult session with a client). According to the model, if the supervisor is appropriately responsive, the relationship forms the secure base from which the trainee can explore and gain competencies. This is contingent on the supervisor's willingness to allow the exploration, as well. In this yet untested model, it is the supervisor's approach to caregiver behaviors that determine the outcome, rather than the trainee's attachment style. While not explicitly factored into the model, attachment style of the supervisor is relevant to his or her 
approach to the attachment cues of the trainee (Riggs \& Bretz, 2006). Therefore, examination of the supervisor's attachment styles may be elucidative.

The majority of the literature discussing supervisor attachment processes is theoretical in nature rather than empirical. However, there are distinct patterns that could be hypothesized for supervisors according to attachment style. For instance, a secure supervisor is dependable and available to his or her trainee's needs, and adaptively respond to trainee attachment cues (Bennett \& Saks, 2006; Pistole \& Fitch, 2008). These responses could be normalization of the student's concerns, enactment of appropriate boundaries and support, and flexibility in interactions. The result should be a more positive supervisory relationship outcome (Watkins \& Riggs, 2012). Alternatively, insecure supervisors may have more difficulty attaining or relinquishing closeness with their students (White \& Queener, 2003). Preoccupied supervisors may appear intrusive or take part in role reversals, while dismissing supervisors may be unavailable, hypercritical, or patronizing (Bennett \& Saks, 2006; Pistole, 2008; Riggs \& Bretz, 2006). Finally, fearful supervisors may be disorganized, vulnerable, and unpredictable. Bennett et al. (2012) found that high anxious attachment was significantly associated with greater negative affect, while high avoidant attachment was marginally associated with negative affect. Overall, negative supervisory relationships are a likely result of insecure supervisors (Foster, Heinen, Lichtenberg, \& Gomez, 2006; Watkins \& Riggs, 2012).

Applying this line of theoretical thought, some studies examining both members of the supervisor/trainee dyad have concluded that supervisor attachment style contributes more variance in working alliance than trainee attachment style (Dickson et al., 2011; Riggs \& Bretz, 2006). For instance, there is evidence that a supervisor's general ability to form attachments in a healthy manner is more associated with working alliance than a trainee’s attachment style (Riggs 
\& Bretz, 2006; White \& Queener, 2003). It should be noted, however, that the few studies that have utilized supervisor-rated data have analyzed that data and student data in separate analyses. Further, other studies examining the dyad have used trainee-rated, perceived supervisor attachment style. Bennett et al. (2013) supplemented this finding with the conclusions that supervisor negative affect positively related to negative alliance, while negative affect in trainees was not associated with supervisory working alliance.

Bennett (2008a) attempted to further examine the attachment/supervisory relationship in an intervention designed as a training program for supervisors in social work. Eight months in total, this program attempted to train supervisors to recognize and respond appropriately to attachment cues demonstrated in their trainees. Follow up examinations of this program (referred to as Developmental-Relational Approach to Field Supervision) suggested that while trained supervisor perceptions of alliance and certain trainee competencies (ability to assess clients, planning and implementing interventions) increased, trainees of trained instructors rated their skills as no different than un-trained dyads (Deal, Bennett, Mohr, \& Hwang, 2011). Comparison of experimental and control group trainee perception of alliance was non-significant, as well. These findings indicate that there may be other factors at play in these relationships, and that measurement of one member of the dyad is insufficient in determination of outcomes.

\section{Supervisory Attachment in Dyadic Interactions}

Evidence from previous research indicates that the interaction between styles may be the most predictive of supervision outcome (Bennett, 2008b, Bennett \& Deal, 2009; Bennett \& Saks, 2006). Watkins (1995) argues that supervisors may get “caught up” in trainee attachment behavior; the opposite could be true for trainees and supervisor attachment behavior. In order to 
examine better the intricacies of these dynamics, the interactions between styles should be considered (Watkins \& Riggs, 2012). Riggs and Bretz (2006) considered the dyadic interaction; however, their study examined perceived supervisor attachment style from the viewpoint of the trainee, which has been associated with the attachment style of the trainees themselves.

Despite the lack of empirical evidence for outcomes relating to dyadic interactions, theorists have addressed the issue. Authors agree that the most effective dyad should be the secure supervisor-secure trainee, while insecure attachment styles in either of the members may result in difficulty (Bennett \& Saks, 2006; Watkins, 1995; Watkins \& Riggs, 2012). Watkins and Riggs hypothesized more specific outcomes in relation to dyads. More specifically, they predicted the following: secure trainee/insecure supervisor pairs will be buffered from negative outcomes in the short-term, insecure trainee/secure supervisor dyads will also have a buffering affect because of objectivity in the secure supervisor, insecure trainee/supervisor pairs will result in the worst outcomes, as both members will likely hold unrealistic views of the other member. These hypotheses have yet to be explored, and take central stage in the current project, further described below.

\section{Working Alliance Expectations}

Also proposed in the Watkins and Riggs review are hypotheses regarding trainee expectations for supervision. These expectations are important in the conceptualization of supervisory attachment because of the possibility that these expectations are illustrative of the trainee's attachment style. Further, according to Watkins and Riggs, initial expectations could alter according to the nature of the supervisory interaction. For instance, while preoccupied trainees may begin supervision with hopeful expectations, preoccupation with the supervisor's 
perceptions of them could impact their view of the process resulting in disappointment. Secure and dismissing/fearful trainees, however, were hypothesized to maintain their viewpoint; secure trainees would remain positive, while dismissing and fearful trainees would have less favorable expectations.

Supervisors, too, likely have expectations aligning with attachment style. While not examined in this project due to sampling restrictions, Watkins and Riggs hypothesized that expectations of supervisors would be similar to that of trainees in secure and dismissing/fearful styles. However, preoccupied styles contained further parceling, mainly that the supervisor's view of self would impact how expectations shift over time (i.e. more uncertainty in selves, greater propensity for role reversals).

\section{Measurement of Supervisory Attachment}

There appears to be a distinction between general and supervisory-specific styles in relation to outcome and supervisory working alliance (Bennett, BrintzenhofeSzoc, Mohr, \& Saks, 2008; Marmarosh et al., 2013; Riggs \& Bretz, 2006; White \& Queener, 2003). While the latter three studies found small but significant associations between students' general attachments and supervisory working alliance, Bennett and colleagues found that attachment that is supervisory specific is the better predictor. The caveat to this finding is that general attachment styles that were avoidant in nature were associated with student perception of insecure attachment to supervisor. Other studies not using the supervisory working alliance found a connection between general attachment styles and supervisory specific styles (Foster, Lichtenberg, \& Peyton, 2007). 
Despite the burgeoning examination of supervision/attachment processes, some researchers argue that conceptualizing the relationship between supervisor and student as attachment relationships may be questionable in nature (Bartholomew \& Thompson, 1995; Bennett, 2008b; Bennett, Mohr, Deal, \& Hwang, 2012; Gunn \& Pistole, 2012; Neswald McCalip, 2001; Watkins \& Riggs, 2012). Rather, there are suggestions that attachment patterns are certainly at play, but not in the strictest sense of the theory. For instance, Bennett and colleagues argue that because most trainees do not experience loss or grief upon separation from the supervisor, the relationship does not represent a pure attachment interaction. However, Foster, Lichtenber, and Peyton (2007) found that trainees reported attachment-like emotions at similar levels to other close relationships. As a result of this disagreement, Watkins and Riggs (2012) suggest that conceptualization of supervision as a leader-follower attachment relationship may be more accurate. It was the intention of this project to frame these relationships in terms of dyadic interactions rather than textbook theoretical attachment relationships and to explore the conceptualization proposed by Watkins and Riggs.

Leader-Follower Relationships

As Watkins and Riggs (2012) suggested, supervisory relationships may best be captured in a leader-follower relationship. These types of relationships still involve attachment dynamics and affective impact but with an implied hierarchical structure (Hess \& Hess, 2008; Keller \& Cacioppe, 2001). Similar to the complementary form of attachment, leaders can act as attachment figures, supplying a safe haven and secure base for their followers (Mayseless, 2010). Popper and Mayseless (2003) suggest that similar to how parent-child interactions influence the 
attachment styles of a child as they age, children may internalize parental models of leadership to use later in life.

Numerous studies have found associations between leadership effectiveness and secure attachment (Berson, Dan, \& Yammarino, 2006; Englund, Levy, Hyson, \& Sroufe, 2000; Mikulincer \& Florian, 1995; Popper, Amit, Gal, Mishkal-Sinai, \& Lisak, 2004; Sharf \& Mayseless, 2009). Secure styles appear more adept at leadership positions, as self-confidence, sensitivity, prosocial attitude, and availability are qualities found in both secure individuals and good leaders (Popper \& Mayseless, 2007). Additionally, secure leaders likely have greater comfort with follower idealization, responding to attachment cues as a secure base rather than distancing or hyperactivation of their own anxiety (Keller \& Cacioppe, 2001; Hansbrough, 2012).

Alternatively, insecure attachment styles may have more difficulty with leadership roles. More avoidant styles may not fulfill the emotional needs of others, while anxious figures may become hyperactivated and preoccupied with the views of those around them (Mayseless, 2010). This strategy could significantly shape decision-making processes in the leadership role. For instance, followers who perceived their leaders as insecurely attached also rated them higher in self-enhancing, control-related, and self-reliance motives, meaning prosocial motives were not readily discerned (Davidovitz, Mikulincer, Shaver, Izsak, \& Popper, 2007). In addition, highly anxious leaders were rated as less capable of stimulating growth and intellectual thought, more emotionally inefficacious, and less conducive to group cohesion (Davidovitz et al., 2007; Keller \& Cacioppe, 2001). Avoidantly-rated leaders were perceived as less capable of serving as a secure base and a general reduction in follower mental health (Davidovitz et al., 2007) However, 
these ratings, similar to studies examining trainee perceived supervisor attachment style, likely contain bias. Some of this bias could source from the follower/trainee style.

Hazan and Shaver (1990) hypothesized individuals who did not have their attachment needs met as children seek to fulfill those needs later with other attachment figures. According to theory, this is a likely process for followers. Followers high in attachment anxiety have higher expectations for their leaders, often idealizing the leader as capable of fulfilling their needs (Hansbrough, 2012). They exhibit more clingy behavior and rate group cohesion as weaker than secure or avoidant individuals (Davidovitz et al., 2007; Keller \& Cacioppe, 2001). Those with an avoidant style create more distance from their leaders; overall they have a more negative view of the leader, the group, and themselves (Davidovitz et al., 2012; Hansbrough, 2012).

The evidence from studies and conceptualizations from theoretical papers paint a picture very similar to that described in the supervisory attachment literature, as first pointed out by Watkins and Riggs (2012). Keller and Cacioppe (2001) discuss the interactional process between leaders and followers, comparable to in other attachment relationships and previously outlined within the supervisory relationship. More specifically, a secure follower is more positive in his or her expectations, which can cause the leader to act similarly positive about their relationship. Avoidant followers expect insensitivity from leaders, which may create an atmosphere of mutual disrespect. Finally, clinging behavior and over idealization from anxious followers may cause leaders to distance. Leaders, too, can enact responses in their followers stemming from attachment styles: a secure leader may be responsive to individual needs of followers, an anxious leader may express doubts about the abilities of his or her follower, impacting the self-efficacy in the follower, and avoidant leaders may act dismissive and express ambivalence about the follower. 
In sum, the power differential inherent in a leader-follower relationship creates a framework amenable to the examination of hierarchically-based supervisory relationships (Watkins \& Riggs, 2012; White \& Queener, 2003). Utilization of the interactional data from supervisory dyads may provide a picture similar to the literature on leader-follower attachment. More specifically, the nature of the supervisory relationship may be more similar to as found in the extant literature on leader-followers than what is found within parent-child, romantic, or peer attachment relationship research. Given the unanswered questions remaining regarding supervision and attachment theory, what follows is a description of the current project, contextualized within the conceptual and empirical work already completed.

\section{Study Hypotheses}

In light of the literature previously reviewed on attachment, supervision, supervisory attachment, and leader-member relationships, this project attempted to contribute to evidence framing attachment theory within clinical supervision and tested the following hypotheses.

Hypothesis 1: Supervisory Expectations and Attachment

Trainee expectations of supervisory working alliance differ by attachment style. As first proposed in Watkins and Rigg's (2012) review, trainees were predicted to enter a supervisory relationship with different expectations according to attachment style. More specifically, secure trainees, who held both positive views of self and others, were expected to hold more positive expectations of their supervisors and the alliance, while preoccupied trainees were expected to hold positive expectations of the supervisor but not the alliance because of feelings of 
unworthiness or overdependence. Fearful and dismissing styles were expected to have negative expectations for the working alliance.

Hypothesis 2: Working Alliance Change Over Time

Supervisory working alliance change over time for supervisors and trainees vary according to attachment style and/or the dyadic interaction of attachment styles. Attachment styles or the interactions of attachment styles in dyads were hypothesized to affect working alliance over the course of supervision. More specifically, preoccupied trainees were predicted to begin supervision with positive expectations but over time rate a decline in working alliance. Secure trainees were expected to continue with positive alliances, while fearful and dismissing trainees were expected to maintain their negative stances.

Implication sections of empirical studies often address the need for supervisor training and emphasize the need for supervisor self-awareness, yet many studies fail to measure the supervisor's experiences in supervision. While this is likely due to the difficulty inherent in recruiting faculty for sensitive studies (Neswald-McCalip, 2001), it is a valuable enterprise to pursue for reasons presented in the previous section. It was predicted that secure trainee/supervisor dyads would avoid negative outcomes, while insecure trainee/secure supervisors would only be buffered in the short term. In addition, secure trainee/insecure supervisor and insecure supervisor/trainee dyads were expected to exhibit the worst outcomes in relation to supervisory working alliance. This was due to the documented effect of supervisor attachment style on working alliance (Bennett, 2008a, Bennett \& Deal, 2009; Bennett \& Saks, 
2006; Watkins, 2011). In an effort to capture variance missing in the extant literature, the dyad was planned as the unit of analysis for this hypothesis. ${ }^{1}$

Hypothesis 3: Leader-Member Attachment Styles in Supervision

Leader-member attachment dynamics explain additional variance in working alliance scores, above and beyond attachment style. As discussed in the section regarding leader-member attachment relationships, Watkins and Riggs (2012) proposed an alternative to the strict complementary/caregiver attachment-style conceptualization. The literature on leader-member attachment styles, while often used in military or group contexts, may apply to supervision due to the hierarchical nature of the relationship (Bernard \& Goodyear, 2009; Hess \& Hess, 2008). If this hypothesis held, there could be more compelling evidence to support the framework of attachment in supervision.

${ }^{1}$ Dyadic ratings were collected from both supervisors and trainees at Time 1 rather than utilization of perception data (Davidovitz, et al., 2007; Riggs \& Bretz, 2006) or conducting separate analyses (Foster, Lichtenberg, \& Peyton, 2007). Time 2 data was only collected from trainees as the measure of working alliance outcome. 


\section{CHAPTER II}

\section{METHODOLOGY}

\section{Participants}

Participants in this project were recruited from the University of North Texas Psychology Clinic over the course of two semesters. Three American Psychological Asssociation (APA) accredited scientist-practitioner programs are affiliated with this clinic including Clinical, Counseling, and Clinical Health Psychology and Behavioral Medicine (which is accredited as a clinical psychology program). Forty dyads were collected overall from two pools: supervisors and supervisees. Thirty-nine of those dyads completed both time points of the study. Dyads were matched based on a priori clinical practicum team assignments. What follows are further descriptions of the sample.

\section{Supervisors}

Supervisors were doctoral-level psychologists either licensed or under the supervision of a licensed colleague. Each supervisor in this project oversaw a team of students (approximately 5-8) in either a summer or fall semester. Eight supervisors participated in this study; their mean age was $50.83(S D=6.76)$. Supervisors (7 men, 1 woman, all European American) were tenure/tenure-track faculty and represented a variety of orientations including cognitive behavioral therapy (CBT; 37.5\%), psychodynamic (25.0\%), and integrative/eclectic (12.5\%). Approximately 37\% of supervisors chose not to disclose their orientations. Further, in an effort to keep confidential faculty responses, demographic variables were kept separate from responses on attachment measures. All other supervisor demographics can be found in Table 1. 
With regard to attachment, the majority of supervisors endorsed a secure attachment style as measured by the Relationship Questionnaire (RQ). One supervisor each selected fearful and preoccupied. Number of study participants the supervisors oversaw ranged from one to seven $($ mode $=6, M=5.78, S D=3.37)$.

Table 1

Supervisor Demographics $(n=8)$

\begin{tabular}{llcc}
\hline \multirow{2}{*}{ Variable } & Category & Frequency & Percentage \\
\hline Gender & Male & 7 & 87.5 \\
& Female & 1 & 12.5 \\
Program & Clinical & 5 & 62.5 \\
& Counseling & 2 & 25.0 \\
& Clinical Health & 1 & 12.5 \\
Ethnicity & European American & 8 & 100.0 \\
& Hispanic/Latino & 0 & 0.0 \\
& Asian American & 0 & 0.0 \\
Marital Status & Not Married/Partnered & 2 & 25.0 \\
& Married/Partnered & 6 & 75.0 \\
\hline
\end{tabular}

Supervisees

Supervisees were currently enrolled, pre-internship doctoral students. They ranged in year in their respective programs from first semester of year one to year five (age $M=26.58$; $S D$ 
= 3.94). Supervisees ( $n=44 ; 13$ men, 31 women) also represented a variety of theoretical orientations (6\% CBT, 10\% psychodynamic, 6.8\% acceptance and commitment therapy, 6\% integrative/eclectic, $4.6 \%$ other, $38.5 \%$ undisclosed). The supervisee sample was more diverse than that of the supervisors, with 72.7\% European American, 18.2\% Hispanic/Latino, and 9.1\% Asian American. A summary of all demographic variables can be found in Table 2.

Table 2

Trainee Demographics $(n=44)$

\begin{tabular}{|c|c|c|c|}
\hline$\underline{\text { Variable }}$ & Category & Frequency & Percentage \\
\hline \multirow[t]{2}{*}{ Gender } & Male & 13 & 29.5 \\
\hline & Female & 31 & 70.5 \\
\hline \multirow[t]{3}{*}{ Program } & Clinical & 23 & 52.3 \\
\hline & Counseling & 14 & 31.8 \\
\hline & Clinical Health & 7 & 15.9 \\
\hline \multirow[t]{3}{*}{ Ethnicity } & European American & 32 & 72.7 \\
\hline & Hispanic/Latino & 8 & 18.2 \\
\hline & Asian American & 4 & 9.1 \\
\hline \multirow[t]{5}{*}{ Year in Program } & First & 13 & 29.5 \\
\hline & Second & 12 & 27.3 \\
\hline & Third & 13 & 29.5 \\
\hline & Fourth & 3 & 6.8 \\
\hline & Fifth & 3 & 6.8 \\
\hline
\end{tabular}




\begin{tabular}{llll} 
Marital Status & Not Married/Partnered & 34 & 77.3 \\
& Married/Partnered & 10 & 22.7 \\
\hline
\end{tabular}

With regard to clinical variables, summer participants received proportionately greater individual $(M=0.84 ; S D=0.24)$ and fewer group $(M=0.30 ; S D=0.45)$ supervision hours over the ten week semester than fall participants (individual $M=0.79 ; S D=0.30$; group $M=1.65 ; S D$ $=0.69$ ) over the 16-week semester. For those clinicians conducting therapy, summer participants accrued an average of 34.76 hours versus 31.08 hours in the fall. Forty-two of the total 44 participants completed both time points. Six supervisees were matched with two different supervisors over the course of the study, creating 39 unique dyads overall that participated in both time one and time two administrations. Approximately 38\% had worked with their current supervisor prior to the study, receiving an average of 12.69 hours supervision with that supervisor previously $(S D=4.78)$. Supervisee attachment style also contained more variety than supervisors, with $63.6 \%$ endorsing a secure attachment style, $18.2 \%$ characterizing themselves as fearful, 4.5\% selecting preoccupied, and $13.2 \%$ endorsing dismissing.

\section{Procedure}

Data collection occurred over two academic semesters (summer and fall). Each round of collection contained two time points in an effort to better understand longitudinal change and attachment style. Time 1 occurred prior to the beginning of the academic semester, while Time 2 took place at the conclusion of the semester. Participation in the project was voluntary, with primary recruitment and data collection taking place via e-mail. Data collection proceeded following the approval of UNT Institutional Review Board and the Psychology Clinic oversight 
committee, and in congruence with APA ethical guidelines. All reasonable effort was extended to de-identify data and maintain confidentiality for participants including third party data entry, use of a participant number system, and separate databases and analyses for demographic information.

Supervisors and supervisees were made aware of the process and expectations of the project prior to making informed consent to participate. Participants were asked to complete the Time 1 measures and return them via e-mail or hard copy. Following the end of the academic semester, participating supervisees were e-mailed the follow up measures and asked to return them in the same manner. Supervisors were recruited at any time during the two academic semesters, as their data was general and contained no specific time limitations.

Both a supervisor and a supervisee did not have to consent in order to take part in the study. While the dyad was the desired unit of analysis in most hypotheses, some individual analyses took place due to sample requirements. This was to ensure that data collection could occur in a timelier manner. In an effort to maintain consistency in time period, dyads were followed for a semester long period whether the supervisor continued on with the team or not into the spring semester. If a supervisee formed a unique dyad with a new supervisor over the summer to fall semester transition, they were recruited again, while repeat dyads were not.

\section{Measures}

In addition to demographic information such as age, sex, ethnicity/cultural background, marital status, program affiliation, therapeutic orientation, and approximate number of supervision hours, the measures that follow were utilized. 
Leader-Member Exchange (LMX; Graen \& Uhl-Bien, 1995). The LMX is a unidimensional measure of leader-member exchange, or the quality of a member's relationship with their leader or a leader’s relationship with their group member (Sparrowe \& Liden, 1997). Items were re-worded to refer to supervisor or supervisee. The measure is 7 items in total, with a 5point Likert-scale that varies depending on item (i.e. 1-rarely, none to 5- very often, very high). Example items include "How well do you (How well does your supervisor) understand your supervisee’s problems and needs?” and "How would you characterize your working relationship with your supervisee (supervisor).” Previous studies reported internal consistency ranges from .80 to .90 (Chen, Lam, \& Zhong, 2012). Gerstner and Day (1997) demonstrated the predictive validity of the 7-item LMX scale, stating it was the most psychometrically sound among LMX measures. Supervisees completed the LMX at Time 1 and Time 2, while supervisors completed it only once. Because of the theoretical nature of the Watkins and Riggs (2012) proposal that supervisory attachment could be contextualized within a leader-follower framework, prior to this study this measure had not yet been published in relation to supervision. Cronbach's alpha for this study ranged from .88 to .92 for supervisees through the four administrations of the measure, while the supervisor administration yielded an alpha of .43.

The Relationship Questionnaire (RQ; Bartholomew \& Horowitz, 1991). This self-report measure of adult attachment styles requires participants endorse one of four short paragraphs, each representing an attachment style (secure, preoccupied, dismissing, fearful). Raters are then asked to select a Likert-scale item indicating to what extent each description characterizes them in close relationships. The scale ranges from 1-not at all like me to 7-very much like me). This measure yields both a categorical, forced-choice style and a continuous metric of secure attachment. Example items include "It is easy for me to become emotionally close to others. I am 
comfortable depending on them and having them depend on me. I don't worry about being alone or having others not accept me" (secure) and "I am comfortable without close emotional relationships. It is very important to me to feel independent and self-sufficient, and I prefer not to depend on others or have others depend on me” (dismissing). Griffin \& Bartholomew (1994) reported measurement of construct, discriminate, and convergent validity. Test-retest reliability has been demonstrated ranging from 8 months to four years (Kirkpatrick \& Hazan, 1994; Herzberg, Hammen, Burge, Daley, Davila, \& Lindberg, 1999; Scharfe \& Bartholomew, 1988). Bartholomew and Horowitz (1991) reported Cronbach’s alpha coefficients from .87 to .95 for each attachment style. This measure has been previously used in supervisory attachment research in several studies (Dickson et al., 2011; Renfro-Michel \& Sheperis, 2009; Riggs \& Bretz, 2006). Supervisors and supervisees completed this measure at Time 1, referring to their own attachment style in close relationships. The forced-choice component of this measure was utilized in this study.

The Relationship Structures Questionnaire (ECR-RS; Fraley et al., 2011). The ECR-RS was developed as a measure of relationship-specific attachment, allowing researchers to identify the relationship to rate. Nine items in total, two scores are derived from the responses: attachment-related avoidance and attachment-related anxiety. Items are rated on a Likert-scale (1-strongly disagree, 7- strongly agree) to indicate agreement with the statement. Examples include "I usually discuss my problems and concerns with my supervisor" and "I often worry my supervisor doesn’t really care for me.” Fraley and colleagues (2011) reported alphas of .85 for anxiety and .88 for avoidance in addition to convergent and discriminate validity. Additionally, test-retest reliability was established for over 30 day periods (Fraley, Niedenthal, Marks, Brumbaugh, \& Vicary, 2006). In this project, supervisees completed this measure about the 
relationship with their supervisors at Time 1 and Time 2. One study examining supervisory attachment utilized a modified version of this measure (Bennett et al., 2008), reporting alpha coefficients of .77 for anxiety and .93 for avoidance. This sample yielded alpha coefficients ranging from .83 to .94 for attachment avoidance and .46 to .54 for attachment-related anxiety.

Working Alliance Inventory- Short Version (WAI-SVO; WAI-SVEE, Tracey \& Kokotovic, 1989). Adapted from the Working Alliance Inventory (Horvath \& Greenberg, 1986, 1989) used for psychotherapy, this briefer, 12-item measure has been used in several studies pertaining to supervisory working alliance (Bennett et al, 2008; Deal et al., 2011; Marmarosh et al., 2013). The words client/therapist were substituted for supervisor/supervisee, depending on the respondent. Participants responded on a 7-point likert scale (1- never to 7-always) to items such as "I appreciate my supervisee (supervisor) as a person” and "We are working towards mutually agreed upon goals.” Previous studies using this modified version have reported alpha coefficients ranging from .92 to .95 for the total scale score. Predictive validity has been established through comparisons with measures of supervisory style and attachment to supervisor (Bennett et al., 2008). Supervisors complete this measure once; supervisees completed the WAI-SVEE at time one about their supervision expectations and time two about their experiences. Alpha coefficients in these samples was .84 for supervisors and ranged from .90 to.96 for supervisees. 


\section{CHAPTER III}

\section{RESULTS}

Prior to any data analysis, data was cleaned, screened for missing data points, and examined for outliers. Missing data was primarily fixed with mean substitution. There were no outliers present in the sample, necessitating no correction. Scaled scores were calculated for each measure following appropriate recoding of necessary variables.

Demographics were analyzed in a data set separate from the other data in an effort to retain confidentiality. Descriptive statistics were calculated including variables of age, sex, ethnicity, marital status, orientation, program affiliation, year in program, approximate number of therapy hours, and approximate number of supervision hours overall. See Tables 1 and 2 for demographic descriptive statistics.

Descriptive statistics (means, standard deviations) were calculated for all scales administered to both supervisors and supervisees. Skewness, kurtosis, and frequencies among categorical variables were examined in order to ensure that appropriate variation was achieved and analyses could continue as planned. Using the Relationship Questionnaire (RQ) categorical variables, supervisor/supervisee dyads were recoded according to their attachment styles (i.e. $0=$ secure supervisor/supervisee, 1 = insecure supervisor/secure supervisee, 2 = secure supervisor/insecure supervisee, 3 = insecure supervisor/supervisee). See Table 3 for categorical attachment style frequencies. Table 4 displays scale means and standard deviations for all scales. 
Table 3

Attachment Style Frequencies

\begin{tabular}{|c|c|c|c|c|c|c|}
\hline \multirow[b]{2}{*}{ Style } & \multicolumn{2}{|c|}{$\underline{\text { Supervisors }}$} & \multicolumn{2}{|c|}{$\underline{\text { Trainees }}$} & \multicolumn{2}{|c|}{ Dyad } \\
\hline & $N$ & $\%$ & $N$ & $\%$ & $N$ & $\%$ \\
\hline Secure & 6 & 75.0 & 28 & 63.6 & & \\
\hline Fearful & 1 & 12.5 & 8 & 18.2 & & \\
\hline Preoccupied & 1 & 12.5 & 2 & 4.5 & & \\
\hline Dismissing & 0 & 0.0 & 6 & 13.6 & & \\
\hline Secure/Secure & & & & & 20 & 40.0 \\
\hline Secure/Insecure & & & & & 12 & 24.0 \\
\hline Insecure/Secure & & & & & 3 & 6.0 \\
\hline Insecure/Insecure & & & & & 5 & 10.0 \\
\hline
\end{tabular}

Table 4

Scale Descriptives $(N=50)$

\begin{tabular}{llcccccc}
\hline & & & \multicolumn{2}{c}{ Time One } & \multicolumn{2}{c}{ Time Two } \\
Group & Scale Name & $N$ & $M$ & $S D$ & $M$ & $S D$ \\
\hline \multirow{2}{*}{ Trainee } & LMX & 50 & 27.18 & 4.89 & 27.83 & 5.03 \\
& ECR-RS Avoidance & 50 & 2.34 & 1.08 & 2.39 & 1.33 \\
& WAI-SVEE & 50 & 66.46 & 9.09 & 66.73 & 11.78 \\
& Wupervisor & WAI-SVOR & 8 & 67.65 & 4.31 & & \\
\hline
\end{tabular}


To determine whether data collected from different semesters could be analyzed concurrently, a MANOVA was conducted with the semester the trainee participated (summer, fall) as the independent variable and time two trainee supervisory working alliance (WAI-SVEE) and supervisory attachment (Experiences in Close Relationships Avoidance subscale; ECR-RS avoidance) as the dependent variables. ${ }^{2}$ Because there was no significant difference found between semesters, analyses continued with combined data.

\section{Bivariate Statistics}

Bivariate correlations for clinical training variables (number of group and individual supervision hours, therapy hours accrued) were examined in relation to scale scores for the variables used in hypothesis testing at both time points and for both supervisors and trainees where applicable (Leader Member Exchange; LMX, ECR-RS avoidance, Working Alliance Supervisee; WAI-SVEE, Working Alliance Supervisor; WAI-SVOR). These correlations are shown in Table 5. Additionally, correlations between the number of hours with the supervisor and the variables of interest (attachment style as measured by the ECR-RS, leader-member exchange as measured by the LMX, and working alliance as measured by the WAI-SVEE/WAISVOR) were obtained in order to determine the need to control for that variable in analyses. Total therapy hours accrued and individual supervision hours were not significantly correlated with any other variables.

Further, for trainees, a positive relationship existed between number of group and individual supervision hours $(r(48)=.41, p=.003)$. Group supervision hours was negatively correlated with attachment-related anxiety $(r(48)=-.32, p=.03)$. All time one measures

\footnotetext{
${ }^{2}$ Due to the poor reliability two measures demonstrated (ECR-RS anxiety and Supervisor LMX), these scales were not included in any analyses.
} 
positively correlated with time two administrations with a medium to large effect. Trainee LMX demonstrated significant negative large relationships with attachment-related avoidance $(r(48)=$ $-.90, p<.001)$ and a large positive relationship with WAI-SVEE $(r(48)=.85, p<.001)$. WAISVEE time two scores were also negatively correlated with ECR-RS avoidance scores with a large effect $(r(48)=-.86, p<.001)$.

Table 5

Bivariate Correlations $(N=50)$

\begin{tabular}{|c|c|c|c|c|c|c|c|c|}
\hline & 1 & 2 & 3 & 4 & 5 & 6 & 7 & 8 \\
\hline 1. Group hours & $\begin{array}{ll}--- \\
-1\end{array}$ & & & & & & & \\
\hline 2. Individual hours & $.41 * *$ & ---- & & & & & & \\
\hline 3. T1 LMX & -.23 & -.16 & ---- & & & & & \\
\hline 4. T2 LMX & .001 & -.08 & $.44^{* *}$ & ---- & & & & \\
\hline 5. T1 ECR-RS avoidance & .15 & -.09 & $-.47 * *$ & $-.60 * *$ & ---- & & & \\
\hline 6. T2 ECR-RS avoidance & -.03 & -.10 & $-.41 * *$ & $-.90 * *$ & $.63^{* *}$ & ---- & & \\
\hline 7. T1 WAI-SVEE & -.24 & -.09 & $.58 * *$ & $.66^{* *}$ & $-.82 * *$ & $-.61 * *$ & ---- & \\
\hline 8. T2 WAI-SVEE & .12 & .11 & $.43 * *$ & $.85^{* *}$ & $-.50 * *$ & $-.86 * *$ & $.58 * *$ & ---- \\
\hline 9. WAI-SVOR & .002 & -.29 & .17 & .04 & -.18 & .01 & .16 & -.09 \\
\hline
\end{tabular}

Note. ${ }^{* *} p<.01 * p<.05$

Supervisory Comparisons

To determine if there were significant differences in how trainees rated their supervisory experiences (time two scores on LMX, ECR-RS avoidance, WAI-SVEE), several analyses were 
performed. First, differences were examined with supervisor as the independent variable using ANOVA. There were significant differences by supervisor for $\operatorname{LMX}(F(11,36)=4.11, p<.001$, $\left.\eta^{2}=.56\right)$, ECR-RS avoidance $\left(F(11,36)=3.19, p=.004, \eta^{2}=.52\right)$, and WAI-SVEE $(F(11,36)=$ 3.51, $p=.002, \eta^{2}=.49$ ), all with large effects. However, there were no significant differences found in trainee's attachment-related anxiety based on supervisor.

Next, $t$-tests examined variables based on whether trainees had ever been on a practicum team with their supervisor prior to the study. There were no significant differences in any of the measures (LMX; ECR-RS avoidance; WAI-SVEE). Similarly, there was no difference in LMX, ECR-RS, or WAI-SVEE scores for supervisors who completed the study measures versus those that declined to participate (LMX; ECR-RS avoidance; WAI-SVEE).

\section{Trainee Attachment Style}

ANOVA was utilized to determine if scores on supervisory variables differed according to attachment, as measured by the RQ. Significant differences were found in time two attachment-related avoidance with large effects $\left(F(3,44)=2.78, p=.05, \eta^{2}=.16\right)$. Using the Games-Howell post-hoc, due to unequal sample sizes, significant mean differences existed between secure $(M=2.23, S D=1.18)$ and preoccupied $(M=1.33, S D=.17)$ styles as well as preoccupied and fearful $(M=3.39, S D=1.80)$ attachment styles. Supervisory specific attachment (ECR-RS) was significantly associated with time two final working alliance scores using a linear regression model and accounted for $72.3 \%$ of variance in WAI-SVEE $(F(2,47)=$ 62.47, $p<.001)$. Attachment related avoidance was a significant predictor $(t(44)=-10.83, p<$ $.001, \beta=-.85)$. 
A calculation was conducted to determine if a significant difference existed between the associations of general attachment (RQ) and WAI-SVEE $(r=.01)$ and supervisory-specific attachment (ECR-RS avoidance) and WAI-SVEE $r=-.86$. There was a significant difference between dependent correlations $(t(45)=8.04, p<.001)$, which indicates that the correlation of supervisory-specific attachment and WAI-SVEE is significantly different than the correlation of RQ and WAI-SVEE.

\section{Hypothesis 1}

Trainee expectations of supervisory working alliance differ by attachment style.

This hypothesis was tested using analysis of variance (ANOVA) to determine if attachment styles (RQ) differed in supervisee expectations for working alliance (expected WAISVEE) with his or her supervisor. If a difference was found, post-hoc tests were used to examine which attachment styles contained the significant findings. There was no difference in expected working alliance based on attachment style.

Additionally, a linear regression was used in order to see if, rather than overall attachment (RQ), the ECR-RS avoidance explained variance in initial WAI-SVEE scores. This model was significant and accounted for $68.7 \%$ of the variance in expectations $(F(2,47)=54.87$, $p<.001)$. Avoidance significantly contributed $(t(46)=-7.72, p<.001, \beta=-.72)$ to the variance in initial WAI-SVEE scores.

Hypothesis 2

Supervisory working alliance change over time for supervisors and trainees will vary according to attachment style and/or the dyadic interaction of attachment styles. 
A mixed ANOVA was completed to determine if there was a significant change in WAISVEE from time one (expectations) to time two (final semester ratings) between general attachment styles, examining if overall student perceptions matched the reality of their expectations. There was not a significant difference between time points nor between attachment styles. Additionally, an interaction between time and RQ styles was not significant.

Trainees

Next, this hypothesis was examined using the categorical RQ as the independent variable and change scores between time one and time two WAI-SVEE as the dependent variable. The change score was designed to capture whether expectations of supervisory working alliance were higher or lower than the working alliance outcome. Linear regression with dummy coded RQ was used to determine if attachment style was associated with working alliance change scores. The model was not significant $(F(3,47)=.701, p=.56)$. Using the ECR-RS avoidance subscale, linear regression was again employed to determine if supervisory specific attachment contributed variance to WAI-SVEE change scores over time. The model was significant $(F(2,47)=5.90$, $p=.005)$ and accounted for $17.2 \%$ of the variance in change between time one and time two. Avoidance was a significant predictor $(t(44)=3.20, p=.003, \beta=.43)$.

\section{Dyadic Interaction}

In order to capture the dyadic interaction of supervisor/trainee attachment styles, the RQ categorical responses for both supervisors and trainees were recoded. Frequencies for this new variable are presented in Table 3. This analysis was completed in order to examine if the change 
in working alliance was associated with interaction of attachment styles. Again, the linear regression using dummy coded dyadic attachment styles from the RQ was not significant.

\section{Hypothesis 3}

Leader-member attachment dynamics will explain additional variance in working alliance scores, above and beyond attachment style.

This hypothesis was examined using hierarchical regression. It was conducted for supervisees in addition to the dyadic interaction. Supervisor data alone was not used due to the likelihood that an analysis of that kind would be insufficiently powered. All analyses utilized Time 2 WAI-S scores as the dependent variable.

Trainees

Hierarchical regression was utilized to examine if LMX contributed variance to WAISVEE scores above and beyond attachment style. The first block, containing dummy coded RQ was not significant $(F(3,47)=.95, p=.42)$. LMX, contained in block two, contributed significant variance to the overall model $(F(4,47)=29.01, p<.001)$. LMX was the only significantly contributor to the model $(\beta=.87, t(42)=10.31)$ explaining $70.5 \%$ of the variance in working alliance scores.

Similar to previous hypotheses, the ECR-RS was used to determine if supervisory specific attachment explained more variance in working alliance than the RQ. Supervisory attachment style, specifically attachment-related avoidance, was a significant predictor when RQ was replaced in the first block $(t(43)=-2.90, p=.01, \beta=-.48)$. LMX also represented a significant predictor in the second block $(\beta=.42, t(42)=2.56, p=.01)$ accounting for an 
additional 3\% of the variance in WAI-SVEE scores $(p=.01)$. The overall model was associated with $75.4 \%$ of the variance in WAI-SVEE scores $(F(3,47)=48.97, p<.001)$.

Supervisors

Due to the poor reliability demonstrated for the supervisor LMX scale in this sample, analysis of hypotheses pertaining to supervisors alone were not performed.

Dyadic Interaction

Using dummy coded dyadic interactions of the RQ and an interaction term created by the product of trainee and supervisor LMX scores, a hierarchical regression was conducted in order to test the interaction between supervisor and trainee attachment styles and LMX scores. See Table 6 for regression data. The first block, containing just the dyadic variable, was not significant, but the addition of the LMX interaction term was associated with $48.3 \%$ of the variance in final WAI-SVEE scores $(p<.001)$. The overall model was significant $(F(4,38)=.26$, $p<.001)$, with the LMX interaction acting as the only significant predictor $(t(33)=5.76, p<$ $.001)$.

Table 6

Hierarchical Regression Analysis Predicting Time Two WAI-SVEE Scores From Attachment and Leader-Member Exchange Interaction $(N=39)$

\begin{tabular}{lcccccc}
\hline & \multicolumn{3}{c}{ Model 1 } & \multicolumn{3}{c}{ Model 2 } \\
\cline { 2 - 7 } Variable & $B$ & $S E$ B & $\beta$ & $B$ & $S E$ B & $\beta$ \\
\hline Secure/secure & -1.62 & 2.94 & -.07 & .96 & 4.02 & .05
\end{tabular}




\begin{tabular}{|c|c|c|c|c|c|c|}
\hline Secure/insecure & -.96 & 4.02 & -.04 & 1.62 & 2.94 & .07 \\
\hline Insecure/secure & 3.79 & 6.78 & .10 & 1.90 & 4.90 & .05 \\
\hline Insecure/insecure & 2.99 & 5.48 & .10 & 3.26 & 3.96 & .07 \\
\hline LMX Interaction ${ }^{\mathrm{a}}$ & & & & .05 & .009 & .71 \\
\hline$R^{2}$ & & .02 & & & .50 & \\
\hline$F$ & & .26 & & & $8.67 * *$ & \\
\hline$\Delta R^{2}$ & & & & & .48 & \\
\hline$\Delta F$ & & & & & 33.18 & \\
\hline
\end{tabular}

Because a significant relationship was discovered between ECR-RS avoidance, LMX, and WAI-SVEE time two scores, another hierarchical regression utilizing all of these variables was completed to determine if the interaction term would be associated with additional variance over just trainee LMX scores. This hierarchical regression used the dyadic RQ interaction in the first block, trainee LMX in the second, and the interaction term (supervisor LMX by supervisee LMX in the third). While the overall model remained significant, the interaction term did not add significantly more variance $(R$ squared change $=.02, p=.21)$ or represent a significant predictor when trainee LMX comprised the second block. Table 7 displays the full regression model.

\section{Table 7}

Hierarchical Regression Analysis Predicting Time Two WAI-SVEE Scores From Attachment, Trainee Leader-Member Exchange, and Leader-Member Exchange Interaction $(N=39)$ 


\begin{tabular}{|c|c|c|c|c|c|c|c|c|c|}
\hline \multirow[b]{2}{*}{ Variable } & \multicolumn{3}{|c|}{ Model 1} & \multicolumn{3}{|c|}{ Model 2} & \multicolumn{3}{|c|}{ Model 3} \\
\hline & $B$ & $S E B$ & $\beta$ & $B$ & $S E B$ & $\beta$ & $B$ & SE B & $\beta$ \\
\hline Secure/secure & -1.62 & 2.94 & -.07 & -1.78 & 2.46 & -.08 & -1.60 & 2.44 & -.08 \\
\hline Secure/insecure & -.96 & 4.02 & -.04 & -1.62 & 2.94 & -.07 & -2.54 & 3.87 & -.05 \\
\hline Insecure/secure & 3.79 & 6.78 & .10 & -3.29 & 4.38 & -.08 & -4.36 & 4.42 & -.11 \\
\hline Insecure/insecure & 2.99 & 5.48 & .10 & -0.6 & 3.55 & -.002 & -4.36 & 3.53 & -.02 \\
\hline LMX & & & & 1.89 & .24 & $.82 * *$ & 2.68 & .66 & $1.16^{* *}$ \\
\hline LMX Interaction ${ }^{\mathrm{a}}$ & & & & & & & -.03 & .02 & -.36 \\
\hline$R^{2}$ & & .02 & & & .65 & & & .67 & \\
\hline$F$ & & .26 & & & 15.98 & & & $13.33^{* *}$ & \\
\hline$\Delta R^{2}$ & & & & & .63 & & & .02 & \\
\hline$\Delta F$ & & & & & 61.77 & & & 1.61 & \\
\hline
\end{tabular}

Note. ${ }^{* *} p<.01{ }^{*} p<.05$

aTrainee LMX by Supervisor LMX 


\section{CHAPTER IV}

\section{DISCUSSION}

Though the extant literature applying attachment to supervision is small, the results of this project contribute evidence that this framework proves useful in the examination of supervisory process. Using many of the theoretical proposals put forth by Watkins and Riggs (2012), this study yielded some interesting findings relating to trainee and supervisor attachment processes in supervision. The strengths of this study are its longitudinal design, measurement of both components of the supervisory dyad, and utilization of an attachment-type framework (LMX), which addresses the hierarchical and attachment-like (while not pure) nature of supervision (Bartholomew \& Thompson, 1995; Bennett, 2008b; Bennett, Mohr, Deal, \& Hwang, 2013; Gunn \& Pistole, 2012; Neswald McCalip, 2001). Additionally, while the application of attachment to supervision has received broad theoretical attention, few empirical studies exist to test proposed hypotheses. What follows is a discussion of the results, placing these findings within the greater context of other researchers’ efforts to better understand supervision and attachment.

\section{General vs. Supervision-Specific Attachment}

Prior to explicating findings related to the hypotheses described earlier, several broad findings must be laid out. First, supervisory specific attachment, not general attachment, was more associated with working alliance in supervision. Some researchers have asserted the same based on their findings (Bennett, BrintzenhofeSzoc, Mohr, \& Saks, 2008; La Guardia, Ryan, Couchman, \& Deci, 2000), while others have still found significant results using general attachment (Marmarosh et. al, 2013). In this study, general attachment styles did not significantly 
differ from one another on most of the variables of interest. This supports the idea that while attachment styles in the strictest sense do not fit the supervisory relationship, there are attachment-type processes that occur (Bennett, 2008b; Bennett, Mohr, Deal, \& Hwang, 2012; Gunn \& Pistole, 2012; Neswald McCalip, 2001).

Further, it is positive that supervisory attachment style (specifically attachment-related avoidance) was related to general attachment styles. Those with preoccupied attachment endorsed lower avoidance in their supervision relationship than those who were secure. Given the high anxiety, low avoidance dynamic of preoccupied styles, several authors hypothesized that those with preoccupied styles would approach supervisors more often, perhaps even being seen as clingy or needy (Neswald-McCalip, 2001; Renfro-Michel \& Sheperis, 2009). Those with secure styles should theoretically be more avoidant of their supervisors than preoccupied styles, maintaining the boundary of the supervisory relationship (Bennett \& Saks, 2006; Riggs \& Bretz, 2006). Additionally, fearful trainees demonstrated less avoidance than preoccupied trainees. This finding, too, is in line with previously conducted research (Marmarosh et. al, 2013). Fearful styles are more likely to waver between closeness and distance in relationships, desiring feedback but avoidant of it (Pistole \& Watkins, 1995).

Supervisory-specific attachment avoidance was also significantly associated with working alliance expectations and final scores. More specifically, lower levels of attachmentrelated avoidance were associated with higher trainee-rated working alliance scores. Previous research supports this finding in that trainees who demonstrate lower levels of avoidance may have a more secure view of others, including their supervisor (Neswald-McCalip, 2001; RenfroMichel \& Sheperis, 2009). They may view the relationship as stronger overall in comparison to those who consistently view others in a negative way. 
The other component of the supervisory-specific attachment measure, attachment-related anxiety, demonstrated very poor reliability in this sample and was not predictive of any outcomes. It is uncertain why this subscale performed poorly. Previous uses of the measure have demonstrated acceptable reliability for the three-item subscale in larger samples (Fraley, Heffernan, Vicary, \& Brumbaugh, 2011) and use in supervisory relationships specifically (Bennett, BrintzenhofeSzoc, Mohr, \& Saks, 2008). Looking at the three items that compose the anxiety scale, it may be possible that in comparison to the avoidance items, which discuss actions like "opening up" or "discussing problems and concerns," the anxiety items may not apply as well to a professional relationship (e.g. I worry that my supervisor doesn't really care for me; I worry that my supervisor may abandon me). While these items certainly tap into attachment anxiety, trainees could have reacted erratically to items that may appear to cross the professional boundary.

\section{Dyadic Interaction}

There were also no significant findings related to the interaction of supervisor/trainee attachment styles. Several previous studies have posited that the supervisor's characteristics are a strong force in the supervisory relationship (Dickson et al., 2011; Riggs \& Bretz, 2006), a finding not supported in this study. However, it should be noted that there were difficulties with the sample itself (i.e. small size, lack of variability in scores) that likely contributed. Had the sample size been larger, a more normal distribution of attachment styles would have likely been present, leading to greater variability in the dyads created. At that point, patterns similar to the theoretical work described by Watkins and Riggs (2012) may have emerged.

It is also possible that a semester may not be a sufficient amount of time to see large shifts in supervisory alliance based on attachment style. Similar studies of attachment in 
psychotherapy that have found the need for longer periods of time to impact a client's internal working model (IWM) (Fonagy et al., 1996; Kinley \& Reyno, 2013; Kirchmann et al., 2012;

Tasca, Balfour, Ritchie, \& Bissada, 2007), a period of a year, rather than a semester might have allowed for meaningful patterns to surface. However, the structure of the supervision model in this training clinic did not easily facilitate a full year data collection; sample size restrictions would have likely been even more concerning.

\section{Hypothesis 1}

The first hypothesis, examining working alliance expectations according to attachment style, demonstrated a similar pattern to that which was described earlier. Trainee expectations did not differ based on general attachment style, but they were associated with supervisoryspecific attachment, showing a negative relationship between attachment-related avoidance and expectations. This finding makes sense given the literature on attachment-avoidance and internal working models. Those with a negative view of others, resulting in fear of closeness inherent in an attachment-avoidant style, will likely not expect positive relationships (Pistole, 2008; Pistole \& Watkins, 1995). Thereby, when queried on their expectations of supervisory working alliance, they would be more likely to predict lower scores.

Another issue to be considered in the discussion of expectations is the possibility that external opinions may play a role in what trainees expect from their supervisors. For instance, if a supervisor has a certain reputation in the department (positive or negative), it is likely that what trainees had already heard biased how they rated working alliance expectations. It is difficult to determine how to control for these predetermined perceptions in a real world setting. Possibly, in order to maximize attachment-related expectations and minimize external sources, trainees 
would need to be solicited for their working alliance expectations prior to entering the training environment in any way. Again, this method would be difficult in light of sample restrictions, but could assure a purer measurement of expectations based on the internal working model of the trainee.

\section{Hypothesis 2}

Trying to parse out distinct patterns attributable to each attachment style, hypothesis 2 was designed to examine the change between working alliance expectations and final scores over the course of a semester. As Watkins and Riggs (2012) described, it was hypothesized that trainees with certain styles would exhibit meaningful shifts (e.g. avoidant trainees would have increases in working alliances scores over time, while preoccupied trainees would have decreases). There was not, however, a marked shift in working alliance scores for the entire sample, nor between attachment styles. This is similar to findings from the Renfro-Michel \& Sheperis (2009) study; both time points in their study (mid-point in the semester, end of semester) contained similar, if not matching results. The discrepancy between the conceptual and the empirical could be due to several reasons previously discussed, including insufficient time passage and the effect of outside information.

Interestingly, all time one measures correlated with their time two administrations, including positive relationships between time one and time two attachment-related avoidance and anxiety. Conceptually, this fits with the assertion that if a person's attachment-related avoidance or anxiety is elevated at time one, it is also elevated at time two. It could also suggest that trainee attachment-related concerns are fairly stable over time, similar to other relationships (Cassidy \& Shaver, 2008; Fraley \& Shaver, 2000; Mikulincer \& Shaver, 2007a; Rholes \& 
Simpson, 2004). This finding is helpful to the overall literature, as this study did not include an intervention component. Therefore, the measurement of supervisory-specific attachment and working alliance were measured without an attempt to modify their manifestation. Though there is one known intervention discussed in the research literature (Bennett, 2008a), the follow up data did not indicate that trainees’ attachment concerns were altered, despite supervisor ratings indicating that they saw improvement in the supervisory relationship and trainee development (Deal, Bennett, Mohr, \& Hwang, 2011). There is additional work needed in order to ascertain the best method of approaching problematic supervisory attachment styles.

Additionally, it may be possible that trainees were accurate in their expectations from the outset. Therefore, it was important to examine the change over time based on the attachment of the trainee. While general attachment styles did not contain a significant difference, supervisoryspecific attachment-related avoidance was once again associated with working alliance change scores. Additionally, avoidance and the change over semester were positively associated, indicating that as avoidance increased, the change between time points increased. Conceptually, this finding is again consistent with the literature in attachment-related avoidance and working alliance. More specifically, a more avoidant trainee could, given a corrective supervision experience, think more positively of his or her supervisor than was initially expected. However, previous researchers have shown that any shift in working alliance is more likely in anxiouslyattached trainees, as their IWMs are more conducive to view others positively (Deal, Bennett, Mohr, \& Hwang, 2011). Similarly, a more secure trainee’s working alliance change scores should not change as drastically, given the trainee's IWM will not bias their expectations negatively (Watkins \& Riggs, 2012). The remaining variance unexplained in change scores, theoretically, could be attributed to the supervisor characteristics (Fitch, Pistole, \& Gunn, 2010; 
Riggs \& Bretz, 2006). However, as outlined earlier, supervisor variables and the dyadic interaction were underpowered and problematic analyses, leading to a non-significant result.

\section{Hypothesis 3}

The final hypothesis sought to examine if leader-member exchange (LMX), and its implied power differential, was a more appropriate framework for attachment in supervision as compared to a reciprocal or complimentary conceptualization (Watkins \& Riggs, 2012). LMX was associated with working alliance scores above and beyond general and supervisory-specific attachment. Additionally, the overall model, including both attachment-related avoidance and LMX explained a significantly large portion of the variance in working alliance final scores. This finding aligns with the conceptual work explained in the Watkins and Riggs (2012) paper; LMX assists with the explanation of the dynamics of clinical supervision. Again, the addition of the dyadic interaction terms was not helpful to the overall model for the reasons previously outlined.

While these results were expected based on theoretical underpinnings, it is important to consider the possibility of criterion contamination. Specifically, are the constructs of supervisory-specific attachment, LMX, and working alliance redundant? Statistically, tolerance and VIF levels were not concerning, indicating that there was not excessive collinearity between the measures. The literature discusses these variables as distinct constructs, as well. Further examination of these measures needs to be completed in order to determine their validity as separate constructs. However, the finding that LMX was a significant contributor to the explanation of working alliance indicates that it is a worthwhile enterprise to pursue in order to better understand the workings of supervisory process. 


\section{Limitations}

There were several limitations in this study that may impact the generalizability of the findings. The primary limitation lies in the sample. First, the supervisor sample was not representative (i.e. sex, ethnicity) of the make up of the clinic supervisors working in the UNT Psychology Clinic. This stemmed from immense recruitment difficulties despite steps taken to reduce time investment and maintain confidentiality. Challenges in collecting faculty and supervisor data are not novel in the supervision literature (Neswald-McCalip, 2001), but other researchers have emphasized the importance of supervisor input in better understanding supervisory process (Bernard, 2005; Ladany et al., 2000; Watkins \& Riggs, 2012; Riggs \& Bretz, 2006). The low supervisor participation affected the study in several ways. It is likely that the small number of participants resulted in the poor reliability demonstrated in the supervisor LMX measure. In the trainee sample, this measure performed with much more internal consistency. Additionally, low recruitment reduced the diversity in attachment styles, and resulted in lower than typical insecure style frequency (Ladany, Constantine, Miller, \& Erickson, 2000) Both of these results impacted the ability to effectively examine the dyadic hypotheses in this study. As discussed previously, this is likely the reason that many studies in this literature examine supervision from trainee perception, including how the trainee perceives their supervisor's attachment style. Despite its utility in research, this methodology is problematic, as the trainee's own attachment concerns are likely to color supervisor observations and expectations (Davidovitz et al., 2007; Riggs \& Bretz, 2006).

As a result of attempts to protect confidentiality and expand recruitment, demographic variables were examined separately from any of the supervisory variables. This meant that a connection could not be drawn between any demographic variables and supervisory attachment. 
In the case of some demographics, previous research does not suggest a connection. For instance, supervisory attachment is considered a transtheoretical model (Pistole \& Watkins, 1995; Watkins \& Riggs, 2012), therefore there was not an anticipated statistical difference based on orientation. Similarly, other studies found level of experience (e.g. year in program, number of total practicum hours) did not affect attachment orientation or working alliance (Renfro-Michel \& Sheperis, 2009; White \& Queener, 2003). The findings in this study used total hours with supervisor and whether or not the trainee had been assigned to the supervisor previously as proxies to prevent bias; both variables were not associated with any of the outcomes. While it is not anticipated that the separate analysis of demographics and supervisory variables influenced the findings, it is still an important to note.

Next, as briefly discussed earlier, the duration of this study may not have been sufficient to capture the emergence of any altered attachment patterns. With the structure of the training clinic, many, if not most dyads could not be followed over the period of an academic year. While inconvenient for the methodology of this project, this structure could be of benefit to the trainees and possibly the clients. More specifically, the variety of orientations and supervisory styles could help combat stagnation and improve client outcomes (Garner, Hunter, Modisette, Ihnes, \& Godley, 2012). For similar reasons as more advanced clinicians seek consultation, different clinicians with distinct expertise are beneficial in many ways. Future studies wishing to examine specific attachment patterns may need to seek out training clinics structured in yearly rotations rather than semesters. The findings of this study did not support the idea that supervisory working alliance changed significantly over the semester; however, that does not mean that changes would not be observed over a longer amount of time. 
Finally, this study used only self-report measures. Measurement of attachment style can also be done using interviews (Adult Attachment Interview, AAI; George, Kaplan, \& Main, 1985), which can reduce impression management and improve reliability. However, due to the difficulties with recruitment even with a low time investment (approximately 10 to 15 minutes), it is unlikely that an interview would have been feasible for the current project. It would be worthwhile for the future to continue developing ideas to assist researchers in striking a balance between practicality and stronger methodological decision-making, especially in areas of challenging recruitment such as supervisor samples.

\section{Implications}

With acknowledgement of these limitations, practical implications can be derived from these findings, particularly as relating to how supervisors approach trainees in supervision. A previous intervention designed to educate supervisors in attachment styles and possible associated behaviors was unsuccessful from the student perspective (Bennett, 2008a). However, this does not mean that any attempt to intervene using an attachment framework is unnecessary. For instance, training supervisors to recognize a trainee's attempts to utilize supervision as a safe haven may facilitate more trust within the dyad, resulting in a greater working alliance (Bordin, 1983; Fitch, Pistole, \& Gunn, 2010; Gunn \& Pistole, 2012; Hess, 2008). Where this study contributes is the reinforcement that supervisory-specific and leader-member attachment should be the constructs of concern, rather than general attachment. Therefore supervisors, and even trainees, cannot assume that a trainee who appears to be securely attached in his or her romantic and peer relationships will also be securely attached in supervision. There was some relationship between supervisory-specific avoidance and general attachment style; however, both supervisors 
and trainees must be aware of attachment-type behaviors in supervision rather than his or her knowledge of what the trainee is generally like.

With regard to expected shifts in attachment over time, it was demonstrated that working alliance is somewhat stable over a semester's duration. However, trainees with greater supervisory-specific attachment-related avoidance did have greater change over the semester. Therefore, supervisors may expect less effective working alliance in the beginning, but more meaningful change over time, from trainees that are initially avoidant. Secure supervisees, conversely, will appear to have fewer fluctuations in the alliance with their supervisors.

Also important for supervisors, leader-member attachment appeared a strong predictor in increased working alliance. This can imply several outcomes. First, there is a hierarchical relationship inherent in a supervisory relationship that assists in its functioning (Bernard \& Goodyear, 2009). Therefore, it is to the benefit of the alliance to maintain that type of relationship. More specifically, supervisor behaviors that include role-reversal, excessive intrusiveness or over-familiarity (all of which could be related to supervisor attachment style; Bennett \& Saks, 2006; Pistole; Riggs \& Bretz, 2006) act as seriously detrimental to the supervisory relationship (Weatherford, O’Shaughnessy, Mori, \& Kaduvettoor, 2008). Thus it is important for supervisors to maintain their role as supervisor, teacher, consultant, monitor, lecturer, etc. rather than other roles that may interfere with the progress of trainee development. One suggestion for maintaining a safe, boundaried atmosphere is an initial discussion with trainees on expectations, tasks, and possible goals for the supervision duration (Bordin, 1983; Ladany \& Friedlander, 1995; Osborn \& Davis, 1996).

Finally, for trainees, this study reinforces the need for growth in the competency of selfawareness (Kaslow, 2004; Rubin et al., 2007). As supervision is a relationship, there is the 
possibility that lifelong, maladaptive attachment patterns may arise in times of stress. Utilizing resources available (i.e. psychotherapy, scientific literature, self-care), a trainee can progress in his or her level of self-awareness in supervision. This may help combat the attachment behaviors that can be considered problematic. Specifically in these findings, more frequent attachmentrelated avoidance was associated with poorer working alliance. This could interfere with acquiring new psychotherapeutic skills and techniques and impede development as a student and burgeoning clinician (Dickson, Moberly, Marshall, \& Reilly, 2011; Deal, Bennett, Mohr, \& Hwang, 2011).

\section{Future Directions}

Based on the findings of this study, there are several directions available for future research. First, it would be more elucidative to study the dyadic interaction with only supervisory-specific attachment rather than using general attachment. As the findings did not support the idea that general attachment was strongly related to supervisory working alliance, it might be best to examine supervisory interactions as a function of how the internal working models of supervisors/trainees affect their self-efficacy in those roles. For instance, while a supervisor or trainee may have a very successful, secure romantic partnership, he or she may be more anxious or avoidant in supervisory relationships (Foster, Lichtenberg, \& Gomez, 2007; Marmarosh et. al, 2013). While this study examined the supervisory-specific attachment of trainees, it did not measure the same construct for supervisors as there was not an appropriate measurement. The ECR-RS would have required significant re-wording in order to tailor to supervisors. It is possible that interactions between trainee and supervisor supervisory-specific attachment might have contributed to the understanding of attachment in supervision. 
Additionally, recent research has identified a connection between fear of compassion and attachment (Gilbert, McEwan, Matos, \& Rivis, 2011; Mikulincer, Shaver, Gillath, \& Nitzberg, 2005). More specifically, those with insecure styles have more difficulty receiving compassion from others, giving compassion to others, and having compassion for the self. This idea could be highly applicable to the idea of supervision. For instance, if avoidantly attached trainees have difficulty receiving compassion from supervisors, the effectiveness of validation or normalization could be highly impacted. Conversely, if anxiously attached trainees have difficulty with self-compassion, it could help explain the difficulty supervisors may have with fluctuating self-view. These three constructs (attachment, supervisory working alliance, fears of compassion) could be interrelated, resulting in greater implications for supervisory process.

Finally, it would be helpful to apply the findings of this study to helping understand client outcome. Connections between supervision and client progress have been uncovered (Callahan, Almstrom, Swift, Borja, \& Heath, 2009; Wrape, Callahan, Ruggero, Watkins, in press: Watkins, 2011), therefore further research in this area is warranted. It is possible that better understanding supervisory-specific attachment or leader-member exchange could influence the way trainees address ruptures or premature termination, two major challenges for clinicians, especially in training facilities (Callahan, Aubuchon-Endsley, Borja, \& Swift, 2009; Callahan \& Hynan, 2005). These are just a few of the numerous avenues to explore in attachment within supervision, as currently much is left uncovered.

\section{Conclusion}

This study examined the application of attachment to the study of psychotherapy supervision. Findings emphasize the need to measure (1) supervisory-specific attachment rather 
than general attachment, (2) the stability of working alliance expectations over time, and (3) the extra contribution of leader-member attachment in the understanding of supervisor/trainee relationship. While the extant literature on this intersection is still in its infancy, implications for effective supervision could contribute to overall efficacy in supervisor-trainee working alliance and further, to client outcome. Also discussed are the challenges of recruiting supervisors in order to examine dyadic interactions. Overall, however, this project contributes supporting evidence for the continued study of attachment-type conceptualizations within clinical supervision. 


\section{REFERENCES}

Ainsworth, M. D. S., Blehar, M., Waters, E., \& Wall, S. (1978). Patterns of attachment. Hillsdale, NJ: Erlbaum.

Ainsworth, M. D. S. (1989). Attachments beyond infancy. American Psychologist, 44, 709-716. doi: $\underline{10.1037 / 0003-066 X .44 .4 .709}$

Bartholomew, K., \& Horowitz, L. M. (1991). Attachment styles among young adults: A test of a four-category model. Journal of Personality and Social Psychology, 61, 226-244. doi:10.1037/0022-3514.61.2.226

Bartholomew, K., \& Thompson, J. M. (1995). The application of attachment theory to counseling psychology. Counseling Psychologist, 23, 484-484.

doi: 10.1177/0011000095233006

Bennett, C. S. (2008a). Attachment-informed supervision for social work field education. Clinical Social Work Journal, 36, 97-107. doi:http://dx.doi.org/10.1007/s10615-007$\underline{0135-\mathrm{Z}}$

Bennett, C. S. (2008b). The interface of attachment, transference, and countertransference: Implications for the clinical supervisory relationship. Smith College Studies in Social Work, 78, 301-320. doi:10.1080/00377310802114635

Bennett, S., Brintzenhofeszoc, K., Mohr, J., Saks, L.V., (2008). General and supervision-specific attachment styles: Relations to student perceptions of field work supervisors. Journal of Social Work Education, 44(2), 75-94.

Bennett, S., \& Deal, K. H. (2009). Beginnings and endings in social work supervision: The interaction between attachment and developmental processes. Journal of Teaching in Social Work, 29, 101-117. doi:10.1080/08841230802238179 
Bennett, S., Mohr, J., Deal, K. H., \& Hwang, J. (2013). Supervisor attachment, supervisory working alliance, and affect in social work field instruction. Research on Social Work Practice, 23, 199-209. doi: 10.1177/1049731512468492

Bennett, S. \& Saks, L. (2006). A conceptual application of attachment theory and research to the social work student-field instructor supervisory relationship. Journal of Social Work Education, 42, 669-682. Retrieved from http://search.ebscohost.com/login.aspx?direct=true\&db=tfh\&AN=22681438\&scope=site

Bernard, J.M. (2005). Tracing the development of clinical supervision. The Clinical Supervisor, 24, 3-21. doi: 10.1300/J001v24n01_02

Bernard, J.M., \& Goodyear, R.K. (2009). Fundamentals of clinical supervision. Boston: Allyn \& Bacon.

Berson, Y., Dan, O., \& Yammarino, F. J. (2006). Attachment style and individual differences in leadership perceptions and emergence. The Journal of Social Psychology, 146, 165-182. doi:10.3200/SOCP.146.2.165-182

Borders, L. D. (1993). Learning to think like a supervisor. The Clinical Supervisor, 10, 135-148. doi:10.1300/J001v10n02_09

Bordin, E. S. (1983). A working alliance model of supervision. The Counseling Psychologist, 11, 35-42. doi: $10.1177 / 0011000083111007$

Bowlby, J. (1973). Attachment and loss, Vol. 2: Separation. New York, NY: Basic Books.

Bowlby, J. (1977). The making and breaking of affectional bonds. British Journal of Psychiatry, 130, 201-210. doi: 10.1192/bjp.130.5.421

Bowlby, J. (1988). A secure base: Clinical applications of attachment theory. London, England: Routledge. 
Brennan, K. A., Clark, C. L., \& Shaver, P. R. (1998). Self-report measurement of adult attachment: An integrative overview. In J. A. Simpson \& W. S. Rholes (Eds.), Attachment theory and close relationships. New York: Guilford Press.

Callahan, J. L., Aubuchon-Endsley, N., Borja, S. E., \& Swift, J. K. (2009). Pretreatment expectancies and premature termination in a training clinic environment. Training and Education in Professional Psychology, 3, 111-119. doi:10.1037/a0012901

Callahan, J. L., \& Hynan, M. T. (2005). Models of psychotherapy outcome: Are they applicable in training clinics? Psychological Services, 2, 65-69. doi:10.1037/1541-1559.2.1.65

Cassidy, J., \& Shaver, P. (Eds.). (2008). Handbook of attachment: Theory, research, and clinical applications (2nd ed.). New York, NY: Guilford Press.

Chen, Z., Lam, W., \& Zhong, J. (2012). Effects of perceptions on LMX and work performance: Effects of supervisor perception of subordinates emotional intelligence and subordinates perception of trust in the supervisor on LMX and, consequently, performance. Asia Pacific Journal of Management, 29, 597-616. doi:10.1007/s10490-010-9210-z

Connors, M. E. (2011). Attachment theory: A “secure base” for psychotherapy integration. Journal of Psychotherapy Integration, 21, 348-362. doi:10.1037/a0025460

Daniel, S. I. F. (2006). Adult attachment patterns and individual psychotherapy: A review. Clinical Psychology Review, 26, 968-984. doi:http://dx.doi.org/10.1016/j.cpr.2006.02.001 Davidovitz, R., Mikulincer, M., Shaver, P. R., Izsak, R., \& Popper, M. (2007). Leaders as attachment figures: Leaders' attachment orientations predict leadership-related mental representations and followers' performance and mental health. Journal of Personality and Social Psychology, 93, 632-650. doi:10.1037/0022-3514.93.4.632 
Deal, K. H., Bennett, S., Mohr, J., \& Hwang, J. (2011). Effects of field instructor training on student competencies and the supervisory alliance. Research on Social Work Practice, 21, 712-726. doi:10.1177/1049731511410577

Dickson, J. M., Moberly, N. J., Marshall, Y., \& Reilly, J. (2011). Attachment style and its relationship to working alliance in the supervision of british clinical psychology trainees. Clinical Psychology \& Psychotherapy, 18, 322-330. doi:10.1002/cpp.715

Ellis, M.V. (2001). Harmful supervision, a cause for alarm: Commentary on Nelson and Friedlander (2001) and Gray et al (2001). Journal of Counseling Psychology, 48, 401406. doi: $\underline{10.1037 / 0022-0167.48 .4 .401}$

Englund, M. M., Levy, A. K., Hyson, D. M., \& Sroufe, L. A. (2000). Adolescent social competence: Effectiveness in a group setting. Child Development, 71, 1049-1060. doi:10.2307/1132343

Falender, C. A., Cornish, J. A. E., Goodyear, R., Hatcher, R., Kaslow, N. J., Leventhal, G., . . . Grus, C. (2004). Defining competencies in psychology supervision: A consensus statement. Journal of Clinical Psychology, 60, 771-785. doi:10.1002/jclp.20013

Feeney, J. A. (1999). Adult romantic attachment and couple relationships. In J, Cassidy \& P. R. Shaver (Eds.), Handbook of attachment: Theory, research, and clinical applications (pp. 355-377). New York: Guilford Press.

Fitch, J. C., Pistole, M. C., \& Gunn, J. E. (2010). The bonds of development: An attachmentcaregiving model of supervision. Clinical Supervisor, 29, 20-34.

doi:10.1080/07325221003730319 
Fonagy, P., Leigh, T., Steele, M., Steele, H., Kennedy, R., Mattoon, G., Gerber, A. (1996). The relation of attachment status, psychiatric classification, and responses to psychotherapy. Journal of Clinical and Consulting Psychology, 64, 22-31.

Foster, J. T., Heinen, A. D., Lichtenberg, J. W., \& Gomez, A. D. (2006). Supervisor attachment as a predictor of developmental ratings of trainees. American Journal of Psychological Research, 2, 28-39. doi:10.1080/10503300600823202

Foster, J. T., Lichtenberg, J. W., \& Peyton, V. (2007). The supervisory attachment relationship as a predictor of the professional development of the trainee. Psychotherapy Research, 17, 353-361. doi:10.1080/10503300600823202

Fraley, R. C., Heffernan, M. E., Vicary, A. M., \& Brumbaugh, C. C. (2011). The experiences in close relationships_-Relationship structures questionnaire: A method for assessing attachment orientations across relationships. Psychological Assessment, 23, 615-625. doi:10.1037/a0022898

Fraley, R. C., Niedenthal, P. M., Marks, M. J., Brumbaugh, C. C., \& Vicary, A. (2006). Adult attachment and the perception of emotional expressions: Probing the hyperactivating strategies underlying anxious attachment. Journal of Personality, 74, 1163-1190. doi: 10.1111/j.1467-6494.2006.00406.x

Fraley, R. C., \& Shaver, P. R. (2000). Adult romantic attachment: Theoretical developments, emerging controversies, and unanswered questions. Review of General Psychology, 4, 132-154. doi:10.1037/1089-2680.4.2.132

Garner, B. R., Hunter, B. D., Modisette, K. C., Ihnes, P. C., \& Godley, S. H. (2012). Treatment staff turnover in organizations implementing evidence-based practices: Turnover rates 
and their association with client outcomes. Journal of Substance Abuse Treatment, 42, 134-142. doi:http://libproxy.library.unt.edu:2076/10.1016/j.jsat.2011.10.015

George, C., Kaplan, N., \& Main, M. (1985). The adult attachment interview. Unpublished manuscript, Department of Psychology, University of California.

Gerstner, C. R., \& Day, D. V. (1997). Meta-Analytic review of leader-member exchange theory: Correlates and construct issues. Journal Of Applied Psychology, 82(6), 827-844. doi:10.1037/0021-9010.82.6.827

Gilbert, P., McEwan, K., Matos, M., \& Rivis, A. (2011). Fears of compassion: Development of three self-report measures. Psychology \& Psychotherapy: Theory, Research \& Practice, 84(3), 239-255. doi:10.1348/147608310X526511

Gnilka, P. B., Chang, C. Y., \& Dew, B. J. (2012). The relationship between trainee stress, coping resources, the working alliance, and the supervisory working alliance. Journal of Counseling and Development: JCD, 90, 63-70. doi: 10.1111/j.1556-6676.2012.00009.x

Griffin, D. W., \& Bartholomew, K. (1994). Models of the self and other: Fundamental dimensions underlying measures of adult attachment. Journal Of Personality And Social Psychology, 67, 430-445. doi:10.1037/0022-3514.67.3.430

Gunn, J. E., \& Pistole, M. C. (2012). Trainee supervisor attachment: Explaining the alliance and disclosure in supervision. Training and Education in Professional Psychology, 6, 229237. doi:10.1037/a0030805

Hansbrough, T. K. (2012). The construction of a transformational leader: Follower attachment and leadership perceptions. Journal of Applied Social Psychology, 42, 1533-1549. doi:10.1111/j.1559-1816.2012.00913.x 
Harris, T. (2004). Attachment and adult psychotherapy (book). Psychology \& Psychotherapy: Theory, Research \& Practice, 77, 136-138. Retrieved from http://search.ebscohost.com/login.aspx?direct=true\&db=a9h\&AN=12725880\&scope=site Hazan, C, \& Shaver, P. (1987). Romantic love conceptualized as an attachment process. Journal of Personality and Social Psychology, 52, 511-524. doi: 10.1037//0022-3514.52.3.511

Hess, A.K. (2008). Psychotherapy supervision: A conceptual review. In A.K. Hess, K.D. Hess, \& T.H. Hess (Eds.), Psychotherapy supervision: Theory, research, and practice ( ${ }^{\text {nd }}$ ed., pp. 3-22). Hoboken, NJ: Wiley.

Hess, T.H., \& Hess, A.K. (2008). On being supervised. In A.K. Hess et al. (Eds.), Psychotherapy supervision: Theory, research, and practice ( $2^{\text {nd }}$ ed., pp. 55- 69). Hoboken, NJ: Wiley.

Herzberg, D. S., Hammen, C., Burge, D., Daley, S. E., Davila, J., \& Lindberg, N. (1999). Attachment cognitions predict perceived and enacted social support during late adolescence. Journal of Adolescent Research, 14, 387-404.

doi:10.1177/0743558499144001

Hill, E. W. (1992). Marital and family therapy supervision: A relational attachment model. Contemporary Family Therapy: An International Journal, 14, 115-125. doi:10.1007/BF00898080

Horvath, A. O., \& Greenberg, L. S. (1989). Development and validation of the working alliance inventory. Journal of Counseling Psychology, 36, 223-233. doi:10.1037/00220167.36.2.223

Kaslow, N. J. (2004). Competencies in professional psychology. American Psychologist, 59(8), 774-781. doi:10.1037/0003-066X.59.8.774 
Keller, T., \& Cacioppe, R. (2001). Leader-follower attachments: Understanding parental images at work. Leadership \& Organization Development Journal, 22, 70-75. doi: $\underline{10.1108 / 01437730110382622}$

Kinley, J. L., \& Reyno, S. M. (2013). Attachment style changes following intensive short-term group psychotherapy. International Journal of Group Psychotherapy, 63, 53-75. doi: http://dx.doi.org/101521ijgp201363153

Kirchmann, H., Steyer, R., Mayer, A., Joraschky, P., Schreiber-Willnow, K., \& Strauss, B. (2012). Effects of adult inpatient group psychotherapy on attachment characteristics: An observational study comparing routine care to an untreated comparison group. Psychotherapy Research, 22, 95-114.

Kirkpatrick, L. A., \& Hazan, C. (1994). Attachment styles and close relationships: A four-year prospective study. Personal Relationships, 1, 123-142. doi:10.1111/j.14756811.1994.tb00058.x

Ladany, N., Constantine, M. G., Miller, K., Erickson, C. D., \& Muse-Burke, J. L. (2000). Supervisor countertransference: A qualitative investigation into its identification and description. Journal of Counseling Psychology, 47, 102-113. doi: 10.1037//0022$\underline{0167.47 .1 .102}$

Ladany, N., \& Friedlander, M. L. (1995). The relationship between the supervisory working alliance and trainees' experience of role conflict and role ambiguity. Counselor Education and Supervision, 34, 220-231. doi:10.1002/j.1556-6978.1995.tb00244.x

Ladany, N., Lehrman-Waterman, D., Molinaro, M., \& Wolgast, B. (1999). Psychotherapy supervisor ethical practices: Adherence to guidelines, the supervisory working alliance, 
and trainee satisfaction. The Counseling Psychologist, 27, 443-475.

doi:10.1177/0011000099273008

La Guardia, J. G., Ryan, R. M., Couchman, C. E., \& Deci, E. L. (2000). Within-person variation in security of attachment: A self-determination theory perspective on attachment, need fulfillment, and well-being. Journal of Personality and Social Psychology, 79, 367-384. doi:10.1037/0022-3514.79.3.367

Main, M., Kaplan, N., \& Cassidy, J. (1985). Security in infancy, childhood, and adulthood: A move to the level of representation. Monographs of the Society for Research in Child Development, 50, 66-104. doi:10.2307/3333827

Marmarosh, C. L., Nikityn, M., Moehringer, J., Ferraioli, L., Kahn, S., Cerkevich, A, Reisch, E. (2013). Adult attachment, attachment to the supervisor, and the supervisory alliance: How they relate to novice therapists’ perceived counseling self-efficacy. Psychotherapy, 50, 178-188. doi:10.1037/a0033028

Mayseless, O. (2010). Attachment and the leader follower relationship. Journal of Social and Personal Relationships, 27, 271-280. doi: 10.1177/0265407509360904

Mikulincer, M., \& Florian, V. (2000). Exploring individual differences in reactions to mortality salience: Does attachment style regulate terror management mechanisms? Journal of Personality and Social Psychology, 79, 260-273. doi:10.1037/0022-3514.79.2.260

Mikulincer, M., Florian, V., Cowan, P. A., \& Cowan, C. P. (2002). Attachment security in couple relationships: A systemic model and its implications for family dynamics. Family Process, 41, 405-434. doi:10.1111/j.1545-5300.2002.41309.x 
Mikulincer, M., Shaver, P. R., Gillath, O., \& Nitzberg, R. A. (2005). Attachment, caregiving, and altruism: Boosting attachment security increases compassion and helping. Journal of Personality and Social Psychology, 89, 817-839. doi:10.1037/0022-3514.89.5.817

Mikulincer, M., \& Shaver, P. R. (2007a). Attachment in adulthood: Structure, dynamics, and change. New York, NY: Guilford Press.

Mikulincer, M., \& Shaver, P. R. (2007b). Attachment, group-related processes, and psychotherapy. International Journal of Group Psychotherapy, 57, 233-45. doi: 10.1521/ijgp.2007.57.2.233

Nelson, M.L., Barnes, K.L., Evans, A.L., \& Triggiano, P.J. (2008). Working with conflict in clinical supervision: Wise supervisor’s perspectives. Journal of Counseling Psychology, 55, 172-184. doi=10.1037/0022-0167.55.2.172

Neswald-McCalip, R. (2001). Development of the secure counselor: Case examples supporting pistole \& watkins's (1995) discussion of attachment theory in counseling supervision. Counselor Education \& Supervision, 41, 18. doi: 10.1002/j.1556-6978.2001.tb01265.x

O’Connor, B.P. (2001). Reasons for less than ideal psychotherapy supervision. The Clinical Supervisor, 19, 173-183. doi: 10.1300/J001v19n02_10

Olk, M. E., \& Friedlander, M. L. (1992). Trainees' experiences of role conflict and role ambiguity in supervisory relationships. Journal of Counseling Psychology, 39, 389-397. doi:10.1037/0022-0167.39.3.389

Osborn, C. J., \& Davis, T. E. (1996). The supervision contract: The Clinical Supervisor, 14(2), 121-134. doi:10.1300/J001v14n02_10 
Pistole, M. C. (2008). Attachment theory in supervision: A critical incident experience. Counselor Education \& Supervision, 47, 193-205. doi:10.1002/j.15566978.2008.tb00049.x

Pistole, M. C., \& Watkins, C. E. (1995). Attachment theory, counseling process, and supervision. The Counseling Psychologist, 23, 457-478. doi: 10.1177/0011000095233004

Popper, M., Amit, K., Gal, R., Mishkal-Sinai, M., \& Lisak, A. (2004). The capacity to lead: Major psychological differences between leaders and nonleaders. Military Psychology, 16, 245-263. doi:10.1207/s15327876mp1604_3

Popper, M., \& Mayseless, O. (2003). Back to basics: Applying a parenting perspective to transformational leadership. The Leadership Quarterly, 14, 41-65. doi:http://dx.doi.org/10.1016/S1048-9843(02)00183-2

Popper, M., \& Mayseless, O. (2007). The building blocks of leader development. Leadership \& Organization Development Journal, 28, 664-684. doi:http://dx.doi.org/10.1108/01437730710823905

Ramos-Sánchez, L., Esnil, E., Goodwin, A., Riggs, S., Touster, L. O., Wright, L. K., ... . Rodolfa, E. (2002). Negative supervisory events: Effects on supervision and supervisory alliance. Professional Psychology: Research and Practice, 33, 197-202. doi:10.1037/0735-7028.33.2.197

Renfro-Michel, E., \& Sheperis, C. J. (2009). The relationship between counseling trainee attachment orientation and perceived bond with supervisor. Clinical Supervisor, 28, 141154. doi:10.1080/07325220903324306

Rholes, W.S., \& Simpson, J.A. (Eds.). (2004). Adult attachment: Theory, research, and clinical implications. New York, NY, US: Guilford Publications. 
Riggs, S. A., \& Bretz, K. M. (2006). Attachment processes in the supervisory relationship: An exploratory investigation. Professional Psychology: Research and Practice, 37, 558-566. doi:10.1037/0735-7028.37.5.558

Rubenstein, C, \& Shaver, P. R. (1982). In search of intimacy. New York: Delacorte.

Rubin, N. J., Bebeau, M., Leigh, I. W., Lichtenberg, J. W., Nelson, P. D., Portnoy, S., \& Kaslow, N. J. (2007). The competency movement within psychology: An historical perspective. Professional Psychology: Research and Practice, 38, 452-462. doi:10.1037/0735-7028.38.5.452

Schamess, G. (2006). Transference enactments in clinical supervision. Clinical Social Work Journal, 34(4), 407-425. doi:http://dx.doi.org/10.1007/s10615-005-0036-y

Scharfe, E., \& Bartholomew, K. (1994). Reliability and stability of adult attachment patterns. Personal Relationships, 1, 23-43. doi:10.1111/j.1475-6811.1994.tb00053.x

Shaver, P., \& Hazan, C. (1987). Being lonely, falling in love: Perspectives from attachment theory. Journal of Social Behavior and Personality, 2,105-124.

Sparrowe, R. T., \& Liden, R. C. (1997). Process and structure in leader-member exchange. The Academy of Management Review, 22, 522-552. doi:10.2307/259332

Tasca, G., Balfour, L., Ritchie, K., \& Bissada, H. (2007). Change in attachment anxiety is associated with improved depression in women with binge eating disorder. Psychotherapy, Theory, Research, Practice and Training, 44, 423-433.

Thomas, J. T. (2010). The ethics of supervision and consultation (Supervision and consultation defined, pp. 4-7). Washington, DC: American Psychological Association. 
Tracey, T. J., \& Kokotovic, A. M. (1989). Factor structure of the working alliance inventory. Psychological Assessment: A Journal of Consulting and Clinical Psychology, 1, 207-210. doi:10.1037/1040-3590.1.3.207

Watkins, C.E., Jr. (1997). Defining psychotherapy supervision and understanding supervisor functioning. In C.E. Watkins, Jr. (Ed.), Handbook of psychotherapy supervision (pp. 310). New York: Wiley.

Watkins, C. E. (2011). Does psychotherapy supervision contribute to patient outcomes? considering thirty years of research. The Clinical Supervisor, 30(2), 235-256. doi:10.1080/07325223.2011.619417

Watkins, C. E., \& Riggs, S. A. (2012). Psychotherapy supervision and attachment theory: Review, reflections, and recommendations. The Clinical Supervisor, 31, 256-289. doi:10.1080/07325223.2012.743319

Weatherford, R., O’Shaughnessy, T., Mori, Y., \& Kaduvettoor, A. (2008). The new trainee: Order from chaos. In A.K. Hess et al. (Eds.), Psychotherapy supervision, Theory, research, and practice ( $2^{\text {nd }}$ ed., pp. 40-54). Hoboken, NJ: Wiley.

White, V. E. Q., John. (2003). Supervisor and trainee attachments and social provisions related to the supervisory working alliance. Counselor Education \& Supervision, 42, 203. doi: 10.1002/j.1556-6978.2003.tb01812.x 